\title{
A Distanced Machinery Controlling and Monitoring Guardian
}

Operating a Mechanical Machine from a Safe, Reliable, Efficient and Economic Manner






\section{A Distanced Machinery Controlling and Monitoring Guardian}

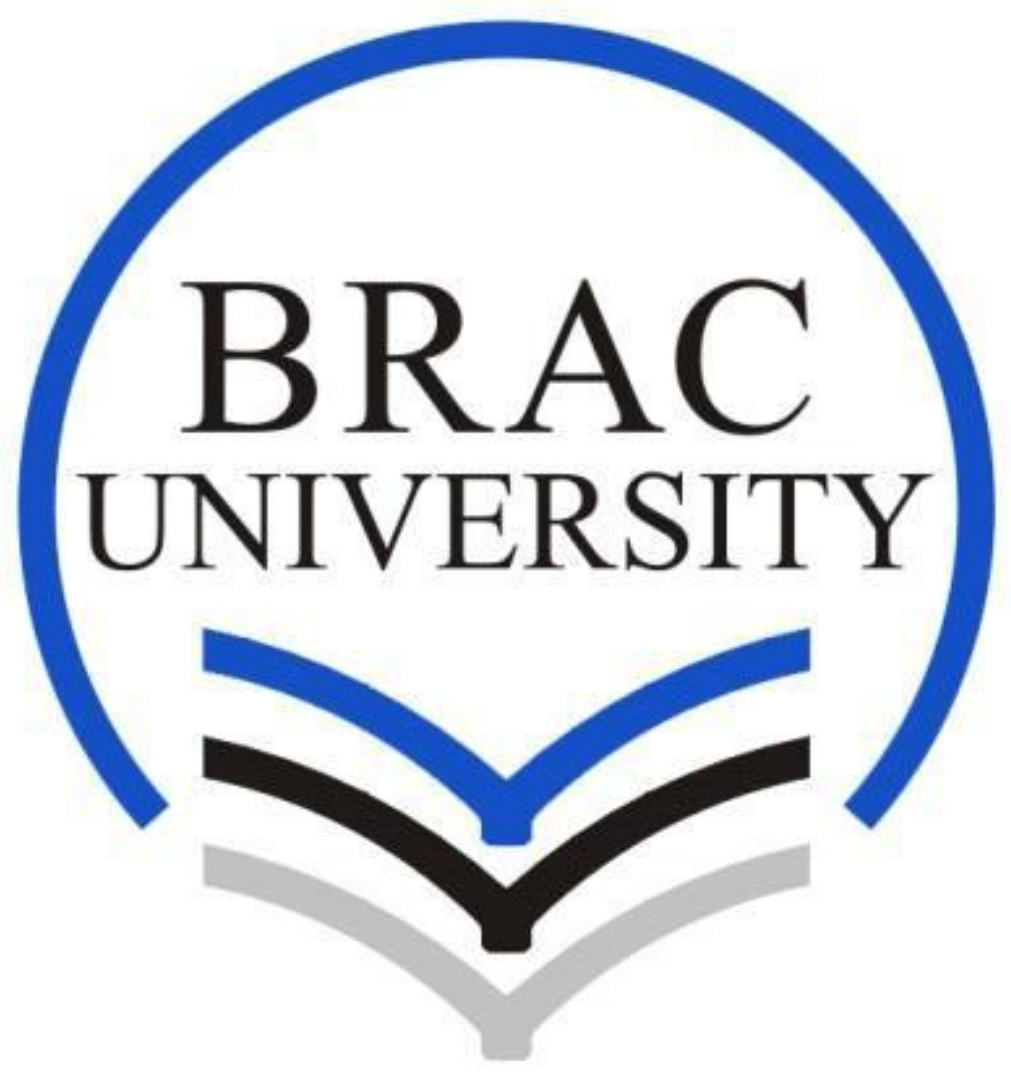

Supervisor: Dr. Md. Khalilur Rhaman

Members:

1. Yaseer Musharraf (09221113)

2. Maruf Hassan (09221021)

3. Shadman Sakib (10121083) 


\section{ABSTRACT}

Every machine has a safe range of operation which includes heat emission, produced sound and vibration which an expert technician can troubleshoot most of the problems just by observing the behavior (sound, vibration, smoke, heat emission etc.) of a machine. But the machine operation complex has a hazardous environment which eventually may cause permanent health damage and it is also expensive as well. Depending upon the machine's purpose, burns, electric shocks and limb amputations are also possible. Where a machine has not been maintained properly, it may malfunction and cause injury to either the operator or other personnel on the ground or in the vicinity. To reduce these problems we are developing a special type of "monitoring system" which will allow us supervise the condition of machine in real time from a safe distance thoroughly with a full control over it. 


\section{CONTENTS}

\begin{tabular}{|l|c|}
\hline \multicolumn{1}{|c|}{ Topics } & Page number \\
\hline Introduction & 5 \\
\hline The Project Co-ordinator & 7 \\
\hline Project Description & $8-18$ \\
\hline Background study & $19-25$ \\
\hline Equipments & $26-27$ \\
\hline Project Working Procedure & $28-29$ \\
\hline Block diagrams & $30-33$ \\
\hline Schematic diagram & $34-35$ \\
\hline Software Building & $36-37$ \\
\hline Timescale & 38 \\
\hline Pitfalls & 39 \\
\hline Expenses & $40-41$ \\
\hline Future plans & $43-50$ \\
\hline future prospect & \\
\hline references & \\
\hline Appendix 1: Self-proposed \& software coding & \\
\hline & \\
\hline & \\
\hline
\end{tabular}




\section{Introduction:}

Machinery parts have its working capability limits under different circumstances and variables. To check whether the machine is working properly or reaching to its danger working state, a monitoring system is must which will help to control the machine in both safe and reliable manner. In olden times it was the role of the watch keeping engineers to monitor and control the machinery parts. This was achieved by periodically taking rounds around the engine room and manually inspecting the condition of the running machinery, which were a very risky job as well as unhealthy and time consuming. This thesis project focuses on the machinery controlling and monitoring to operate a mechanical machine from a safe, reliable, efficient and economic manner. 


\section{The Project Coordinator:}

Our project was coordinated by Dr.Md. KhalilurRhaman(Associate Professor), room no: '50304' in the Department of Computer Science and Engineering, Email: khalilur@bracu.ac.bd.

We arranged regular meetings with $D r . M d$. KhalilurRhaman. The meetings were brief, we contact him once per week to let him know about our working progress and based on his opinion we decided our next step to move forward with our project. We used to take notes during the meeting so that we do not forget conclusions that were reached. 


\section{Project Description (In brief):}

Our project is based on a few basic sensors, which will collect data accordingly, and depending on those values, we can understand the current state of machinery in real time. It is important as all the mechanical as well as electrical equipments to have an ambient zone to work properly and efficiently with a minimal possibility of error in output results. Different equipments have different type of effect on it depending on its type and nature. Its manufacturers predetermine it. As it is variable, we can reconfigure our system according to the necessity very quickly and easily and according to the manufacturers to set the safe zone of an operation level for that.

Depending on its application and utility, every machine have a set of parameters which have to be maintained to get the optimum performance. Apart from that, the output will be affected and thus the lifespan will decrease. There can be many variables, but we will work only on a few parameters. At this stage, with our "Smart Monitoring System" we will start working with a few parameters.

Initially, our goal is only to find the temperature, humidity, smoke leakage and vibration of a machine or a specific area or a room in real time. And then show this data into a computer by interfacing through a software build by Python; using humidity sensor (HSM20g), temperature sensor (LM-35), smoke sensor (MQ-5) and a vibration sensor (SW18015) with the help of a micro controller (pic18F2550).

The software have the ability to show weather the room or the surrounding environment of the piece of equipment is on ambient condition or in a threatening situation and then warn the operator. 


\section{Background Study:}

We decided to conduct our research on ship engine room accidents and to mark it as our main background reason of our project. Based on an article "10 Extremely Dangerous Engine Room Accidents on Ships" ${ }^{[1]}$, Posted in: Maritime Security, October $14,2013^{[4]}$, we managed to come up with some ideas of using some sensor with ship engine room elements, which will help to reduce manually human maintenances errors and provide safe working environments for the workers.

The ship's engine room is the home to a variety of machinery and systems, which work together to move the ship from one port to another. Engine room professionals have to continuously work amidst such high temperature and pressure systems, which make an extremely hostile working environment.

In spite of taking all the precautions and safety measures while handling engine room machinery systems, accidents are bound of take place in the ship's engine room. Many of these accidents are extremely dangerous not only to the ship's properly but also the lives of seafarers. Mentioned below are ten such types of extremely dangerous engine room accidents that occur in ship's engine room.

\section{Crankcase Explosion of Ship's Engine}

Explosion of ship's crankcase is one of the most dangerous accidents in the ship's engine room which has led to devastating consequences, including loss of lives in the past. 
In the engine crankcase, oil particles are churned into smaller particles of up to 200 micro meters in diameter. These small particles cannot ignite readily even with some naked flame. However, if a hot spot comes in contact with these small particles, it reduces the size of the particles, resulting in the formation of mist, which can be readily ignited with a hot spot.

In the crankcase, all the three elements required for fire are available - lubricating oil (fuel source), air, and heat from a hot spot. Coming together of all these three elements can lead to a major explosion that will not only damage the engine but also take lives of crew members.

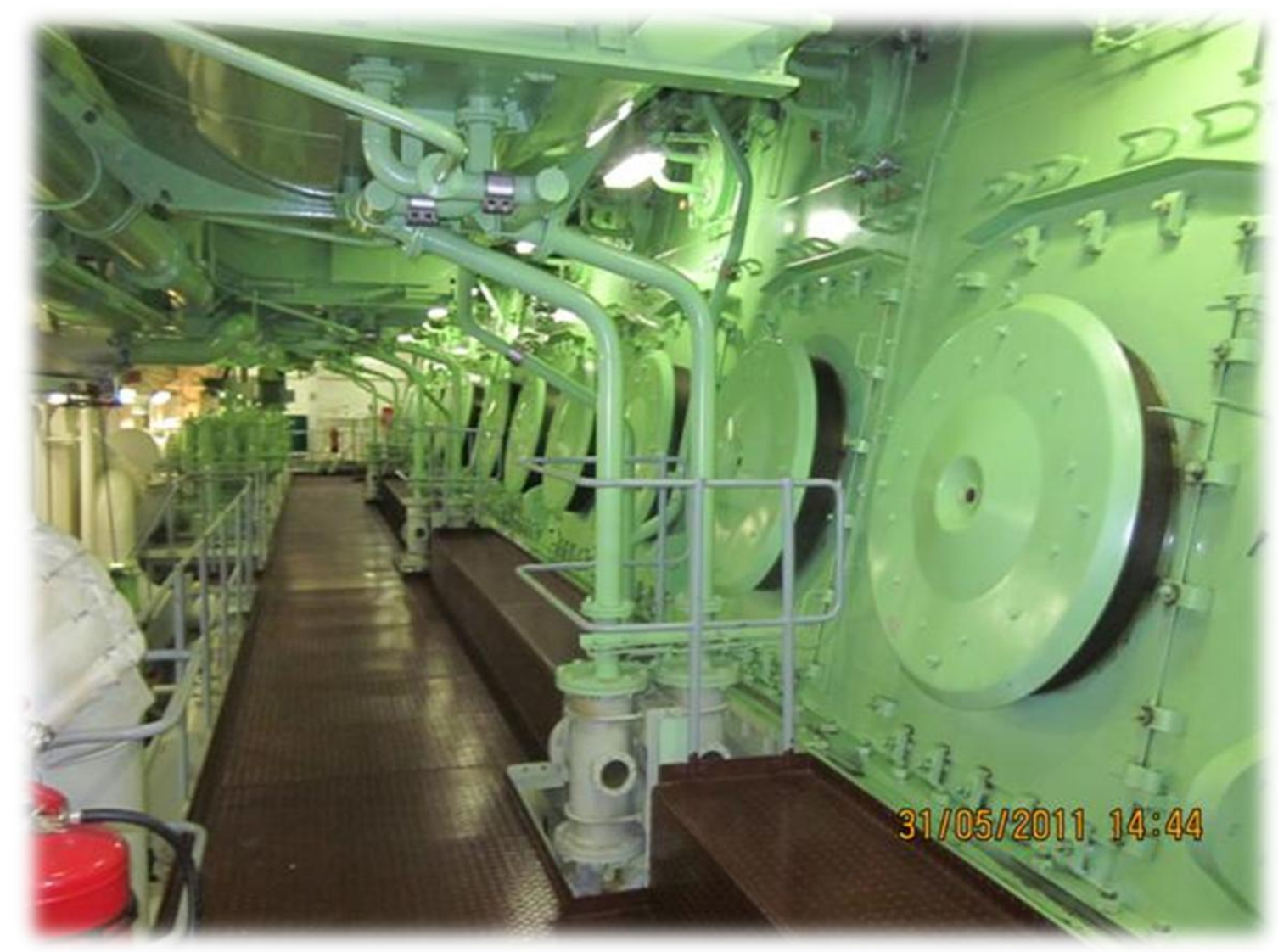

fig: Crankcase of ships' engine room. 
In a situation like this a temperature sensor, humidity sensor and a smoke sensor can be very useful, to detect the over rising heat, humidity and smoke leakage, and give updated information or data to the maintenance group from preventing explosion occurrences by proper monitoring results.

\section{Over-Speeding of Generators}

This kind of accidents though rare have occurred in the past, causing heavy damage and loss of lives. When the ship's generator starts, there are high changes of it to over-speed. If this occurs and the over-speed trip fails to work properly, the high RPM of the generator leads to failure of internal parts. When such situation go out of control, the internal parts such as crank shaft, connecting rod, nut-bolts etc. become loose, get detached, and are thrown away because of the high speed. If crew members do not evacuate the surrounding place in time, the loosen parts can severely harm the crew members.

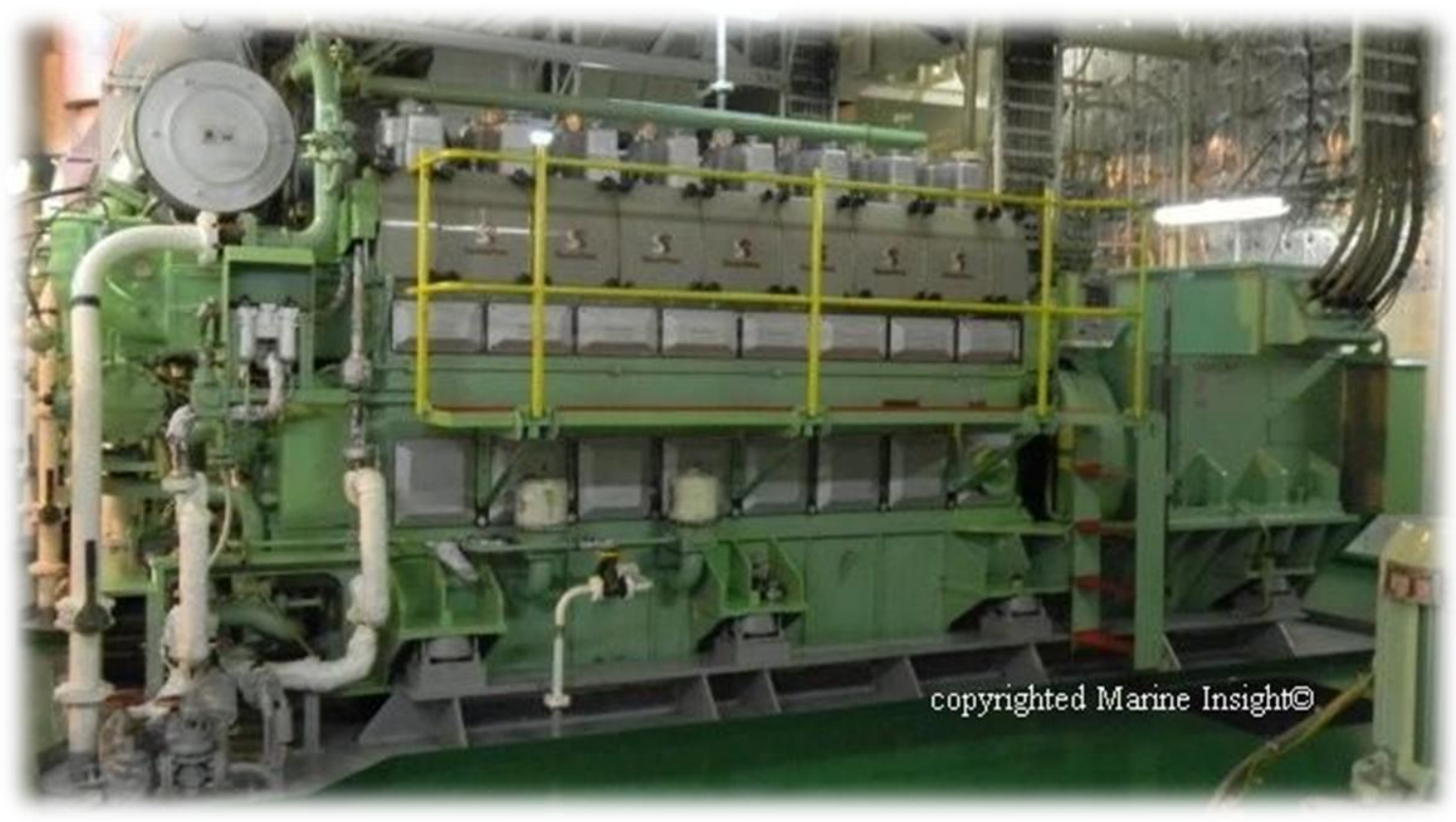

fig: Generators of ships' engine room. 
In a situation like this a vibration sensor can be very useful, to detect the vibration level and compare the result with the normal vibration level, and give updated information or data to the maintenance group from preventing unexpected occurrences by proper monitoring results.

\section{Boiler explosion}

Everyone working on ships has heard about boiler explosion as one of the most deadly accidents in the ship's engine room. A highly pressurized equipment on board ships, boiler has been attached to different kind of accidents as a result of mistakes while operating them. Boiler explosion is one such dangerous accident which is caused because of the following reasons:

- Fuel dripping inside the furnace of the boiler. If the dripping is more and the boiler is fired after an interval, it can lead to blowback and even explosion.

- Misfiring

- Overheating of boiler due to loss of water circulation

- No pre and post purging

- Exhaust gas boiler fire 


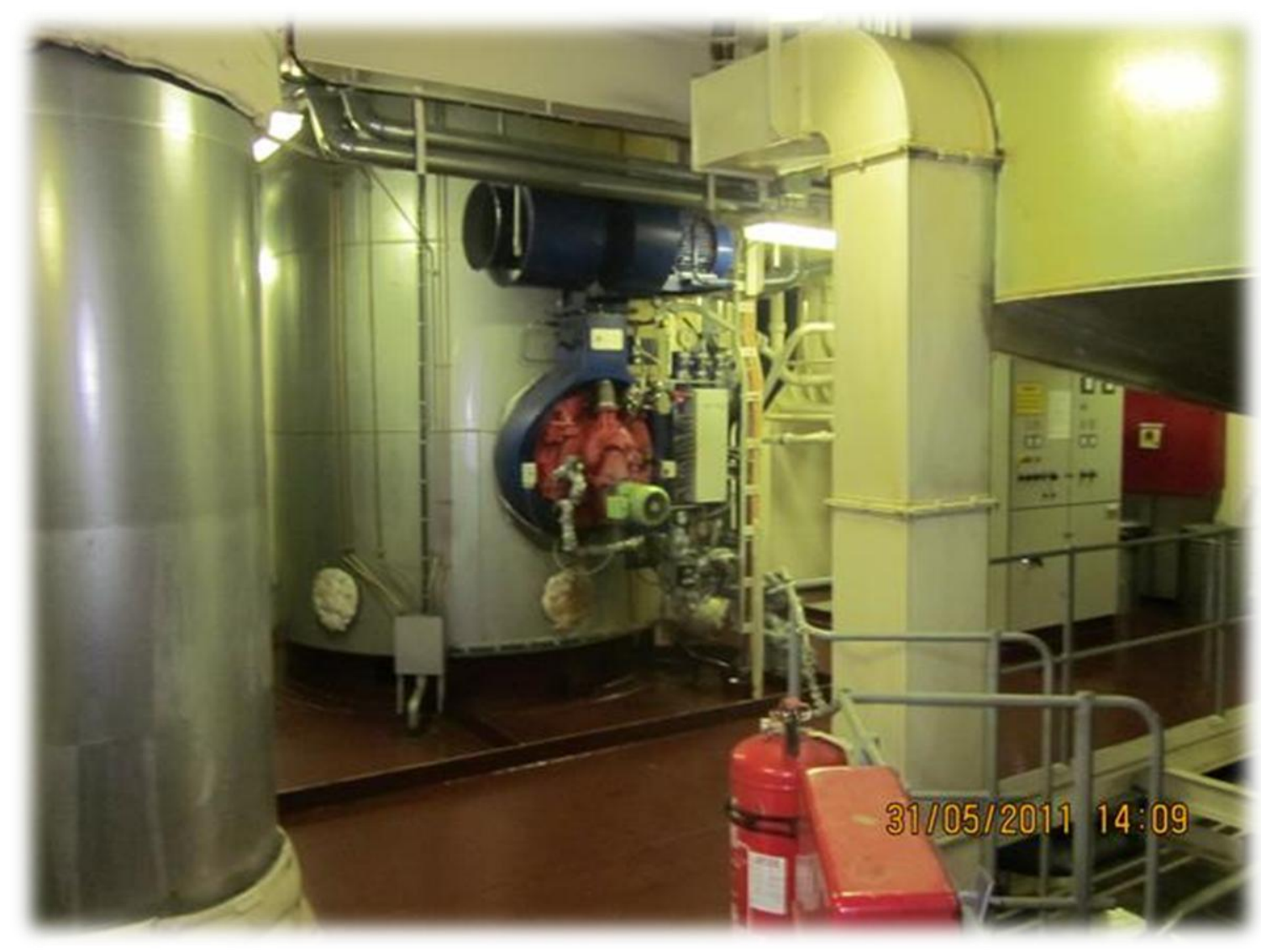

fig: Boiler of ships' engine room.

In a situation like this a temperature sensor, humidity sensor and a smoke sensor can be very useful, to detect the over rising heat, humidity and smoke leaking, and give updated information or data to the maintenance group from preventing explosion occurrences by proper monitoring results.

\section{Compressor Airline Explosion}

Air compressor on ships is also a highly pressurized equipment that can cause deadly accidents. Compressor's airline explosion is one accident everyone is afraid of. Such explosions usually occur when during maintenance; the discharge air valve in the line is closed. There is also a common practice among seafarers to shut the discharge valve of the air compressor to minimize air leakage. But when this 
discharge valve is not opened again while starting the compressor and if the relief valves fail to operate, the airline gets over-pressurized and explodes.

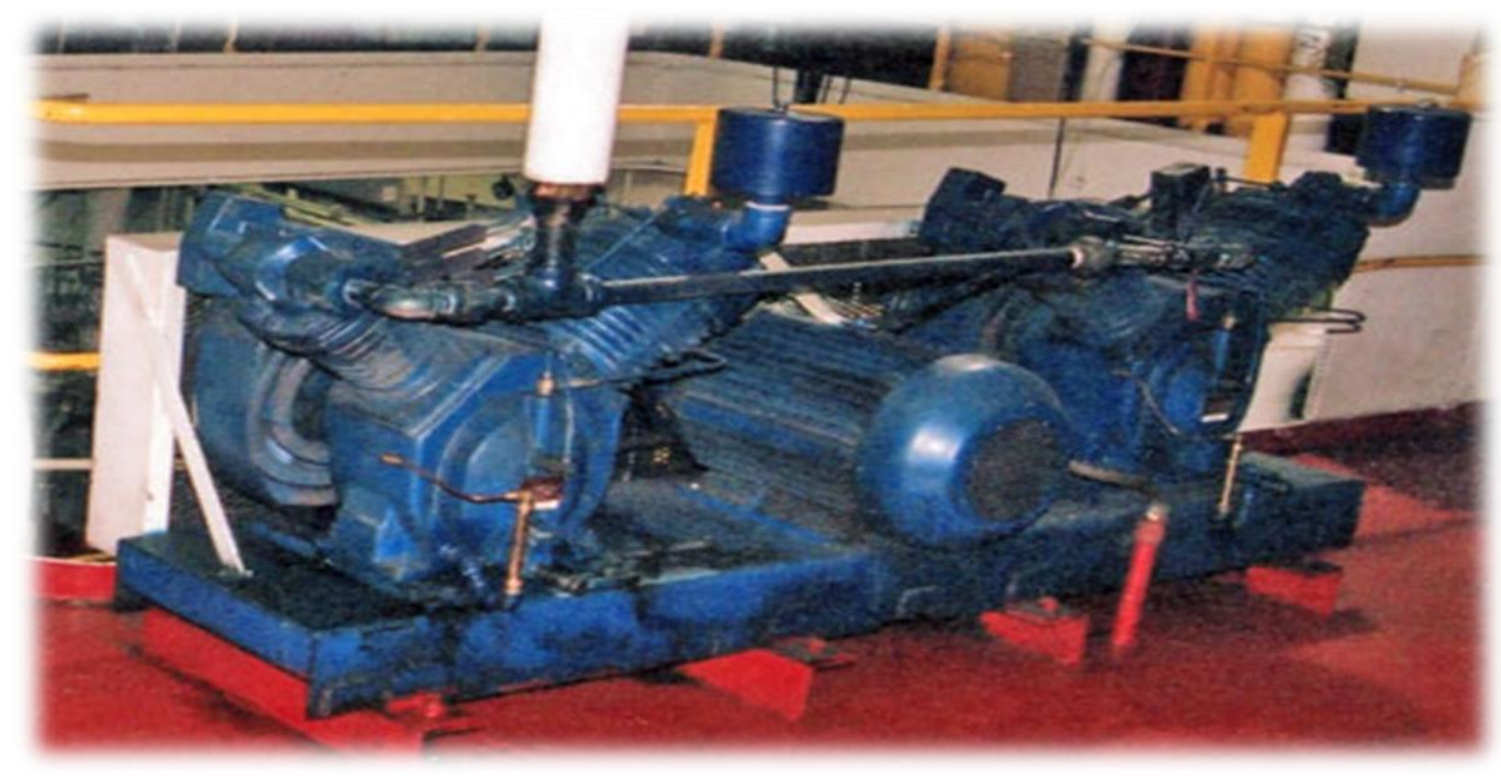

fig: Compressor of ships' engine room.

In a situation like this a vibration sensor and a gas sensor can be very useful, to detect the vibration level and gas leaking, and give updated information or data to the maintenance group from preventing explosion occurrences by proper monitoring results.

\section{High Pressure Fuel Line Bursting}

All high pressurized lines and equipment on board ships are accident prone. The high temperature and pressure fuel line which supplies fuel to the combustion chamber of marine engines can explode if proper maintenance is not carried out. Also, if the lines are not adequately secured, they can burst due to continuous vibrations and friction. Fuel line bursting leads to severe burns, injury and even death of seafarers. 
As per regulations, all high pressurized pipes must be jacketed type to avoid chances of fuel leakages and sprays from the pipe joints.

In a situation like this sound sensor, vibration sensor and a smoke sensor can be very useful, to detect the over rising heat, vibration and smoke, and give updated information or data to the maintenance group from preventing explosion occurrences by proper monitoring results.

\section{High Pressure Steam Leakages}

High pressurized steam lines are present in several parts of the ship's engine room. These high temperature steam lines when burst or crack, lead to leakage of steam at extremely high pressure. Steam burns are extremely dangerous and can even cause instant death. Accidents due to steam leakages can occur because of following reasons:

- Failure of steam joints.

- Steam burns or scalding from opening of boiler mounting valves if not properly isolated or de-pressurized.

- Steam line bursting due to failure of material or crack from vibration or if not properly secured.

In a situation like this a vibration sensor and a humidity sensor can be very useful, to detect the vibration level and humidity, and give updated information or data to the maintenance group from preventing explosion occurrences by proper monitoring results. 


\section{Hydraulic High Pressure Components Bursting}

Hydraulic high pressure equipment tools are used during overhauling of ship's machinery and other important systems. If these high pressure systems are not properly tested before use, it can lead to bursting of their high pressurized parts and causing serious injury to the ship's crew operating them. Some of the major types of hydraulic high pressure accidents are:

- Hydraulic jack oil seal leakage

- Hydraulic jack oil pipe fracture resulting in high pressure jet of oil

- Loose or worn-out connection between jack and pipe causing snapping of pipe which can harm the user

In a situation like this a vibration sensor, humidity sensor and a smoke sensor can be very useful, to detect the vibration level and gas leaking and amount of smoke, and give updated information or data to the maintenance group from preventing explosion occurrences by proper monitoring results.

\section{Turbo Charger Explosion}

Turbo charger explosion on ships is caused when turbochargers are not cleaned for a long time. When the parts of turbo charger are not cleaned properly, the carbon deposits do not allow the parts to cool down properly. As a result, when the oil gets into the exhaust side of the turbo charger through the cracks, the heated parts and fuel source form the perfect combination of an explosion. 


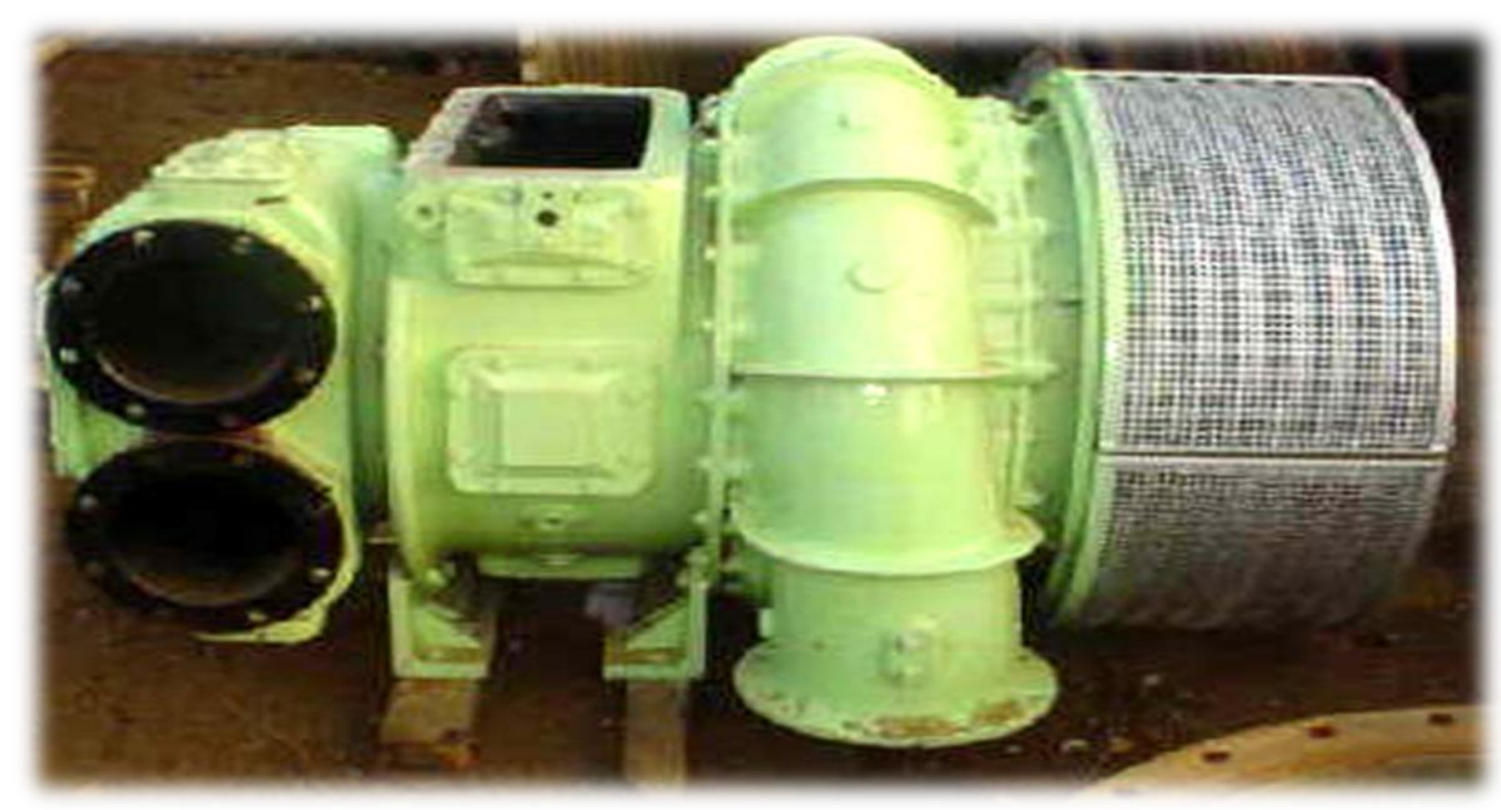

fig: Turbo Charger of ships' engine room.

In a situation like this a vibration sensor can be very useful, to detect the vibration level, and give updated information or data to the maintenance group from preventing explosion occurrences by proper monitoring results.

\section{Electrical Shocks}

Equipment and cables carrying high electrical power are extremely dangerous for people working on ships. If any kind of maintenance is carried out on such systems without isolating them properly, then there are high chances of getting electrical shocks. Moreover, accidental starting of electrical equipment during maintenance has also been a serious cause of seafarers' deaths in the past. Electrical shocks frequently occur on board ships and therefore adequate precautions must be taken to prevent them. 


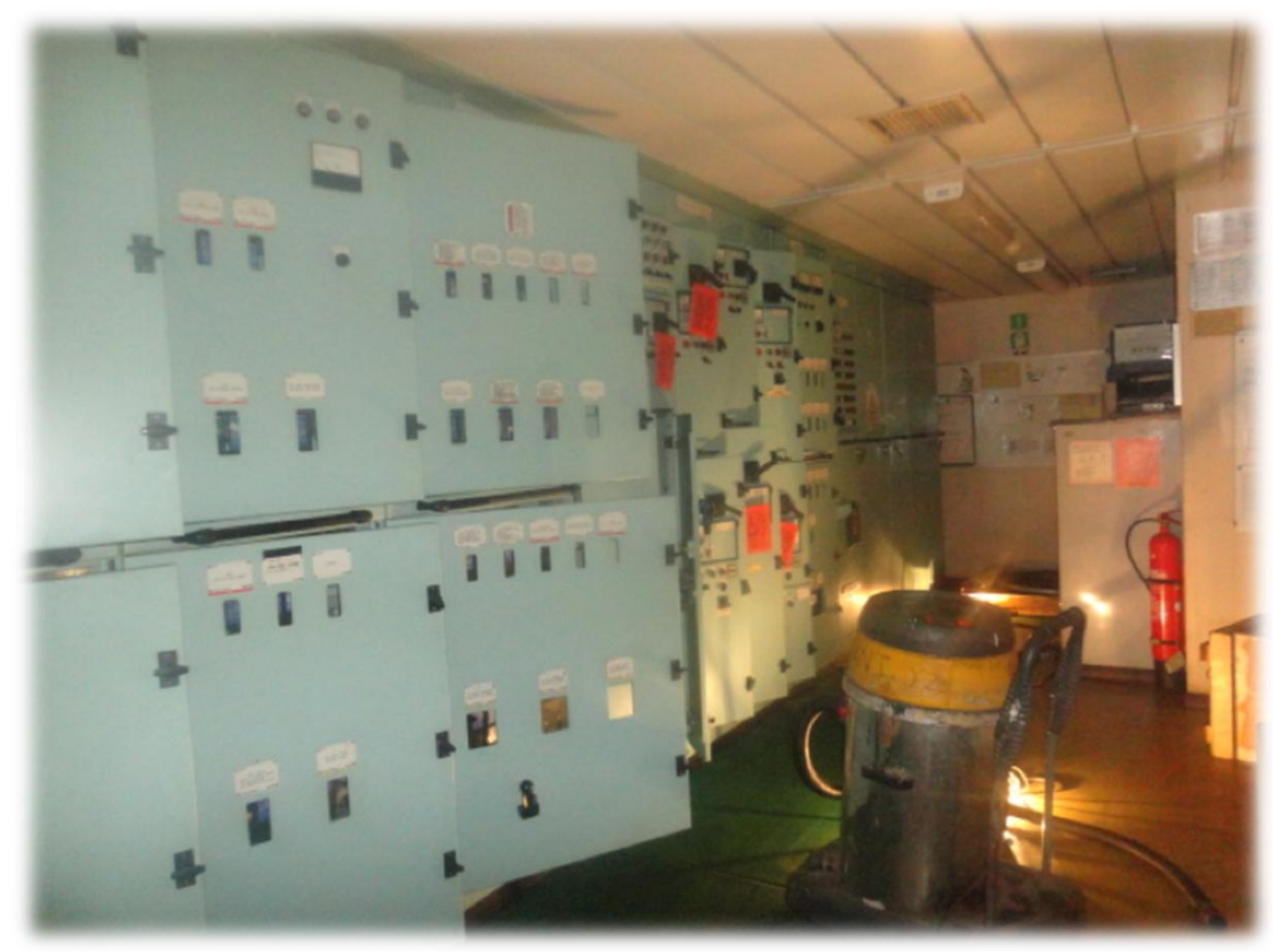

fig: Electrical Shocks of ships' engine room.

\section{Accidental CO2 Release}

$\mathrm{CO} 2$ system is used to release $\mathrm{CO} 2$ in the ship's engine room during fire emergencies only after all the crew has left the engine room. But accidental release of $\mathrm{CO} 2$, when the crew members are still present in the engine room, would lead to instant and tragic death of all. Cases of accidental $\mathrm{CO} 2$ release in the ship's engine room have caused several deaths in the past.

Note: While testing engine room $\mathrm{CO} 2$ alarm, the $\mathrm{CO} 2$ pilot bottles should be properly isolated. 


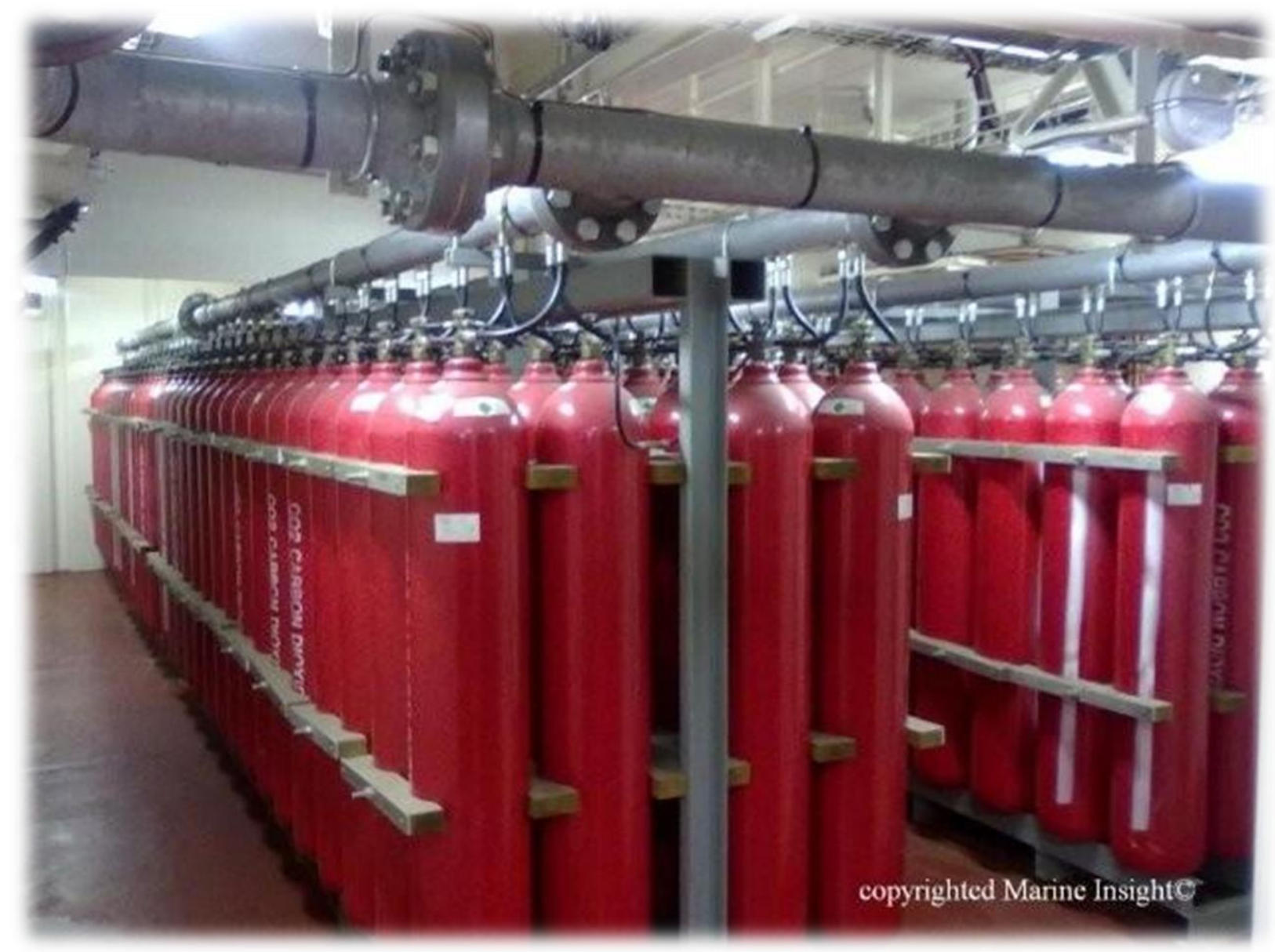

fig: $\mathrm{CO} 2$ tanks of ships' engine room.

In a situation like this a gas sensor can be very useful, to detect the gas leaking amount, and give updated information or data to the maintenance group from preventing explosion occurrences by proper monitoring results. 
Equipments:

1. Pic 18 F2550

2. Sensors:

I. Smoke (MQ5)

II. Humidity (HSM-20g)

III. Temperature (LM-35)

IV. Vibration (SW18015)

3. USB Cable

4. USB Controller

5. POT

6. Resistors:

\begin{tabular}{|l|c|}
\hline Type & No: of resistors \\
\hline $1 \mathrm{k}$ & 2 \\
\hline $2.2 \mathrm{k}$ & 2 \\
\hline $10 \mathrm{k}$ & 1 \\
\hline
\end{tabular}

7. Crystal Oscillator 


\section{Pic18F2550}

PIC ${ }^{[2],[3]}$ is a family of modified Harvard architecture microcontrollers made by Microchip Technology, derived from the PIC1650 originally developed by General Instrument's Microelectronics Division. The name PIC initially referred to "Peripheral Interface Controller". ${ }^{[1]}$

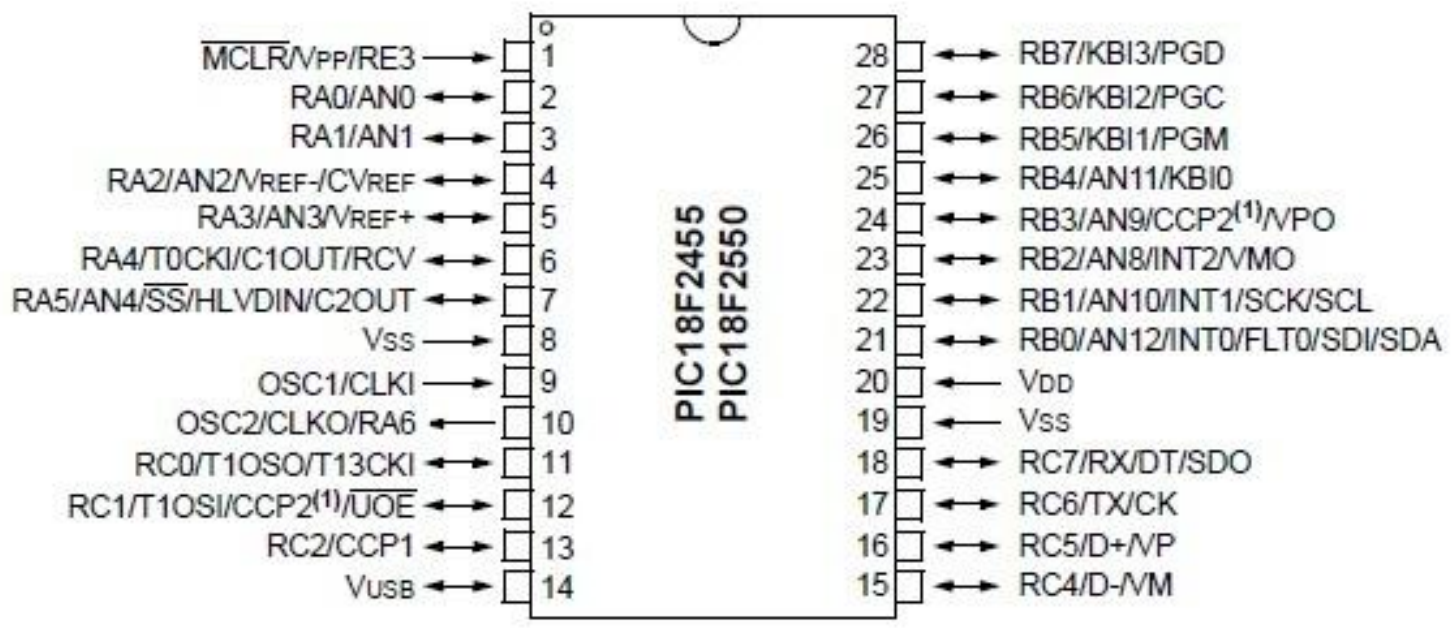

\section{HSM20G:}

The module of HSM-20G ${ }^{[5]}$ is essential for those applications where the relative humidity can be converted to standard voltage output.

\section{STANDARD CHARACTERISTICS}

\begin{tabular}{|l|l|l|l|l|l|l|l|l|l|}
\hline$\%$ RH & 10 & 20 & 30 & 40 & 50 & 60 & 70 & 80 & 90 \\
\hline Output & 0.74 & 0.95 & 1.31 & 1.68 & 2.02 & 2.37 & 2.69 & 2.99 & 3.19 \\
\hline
\end{tabular}

From the graph it is easily seen that the humidity and output relationship is not linear. For this reason, we had to use the curve fitting method to define an input output relationship which can be characterized as follows: 


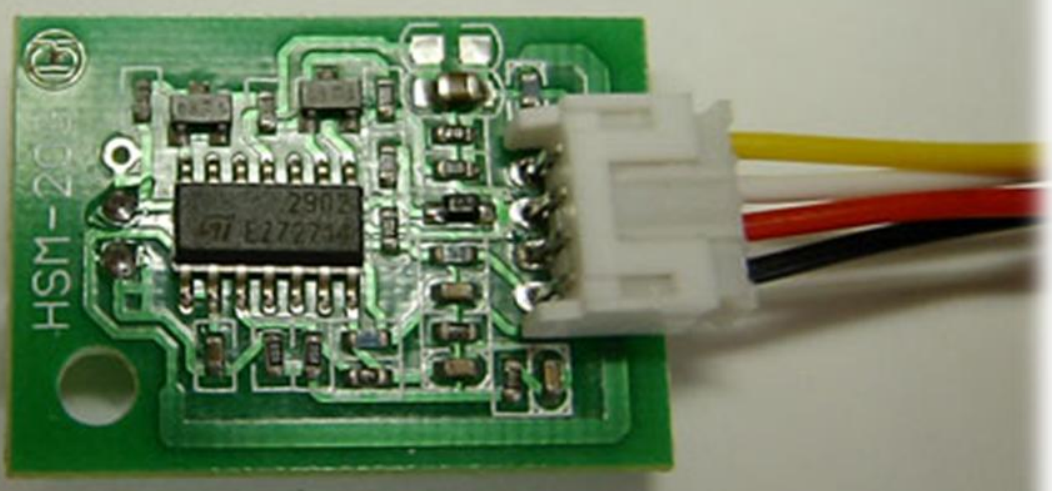

Humidity $=3.71 *$ voltage $^{3}-20.65 *$ voltage $^{2}+64.81 *$ voltage -27.44

Here, voltage is the input value directly obtained from the sensor.

\section{LM35:}

The $\mathrm{LM} 35^{[6]}$ series are precision integrated-circuit temperature sensors, whose output voltage is linearly proportional to the Celsius (Centigrade) temperature. The LM35 thus has an advantage over linear temperature sensors calibrated in ${ }^{\circ}$ Kelvin, as the user is not required to subtract a large constant voltage from its output to obtain convenient Centigrade scaling. The LM35 does not require any external calibration or trimming to provide typical accuracies of $\pm 1 / 4^{\circ} \mathrm{C}$ at room temperature and $\pm 3 / 4^{\circ} \mathrm{C}$ over a full -55 to $+150^{\circ} \mathrm{C}$ temperature range. 


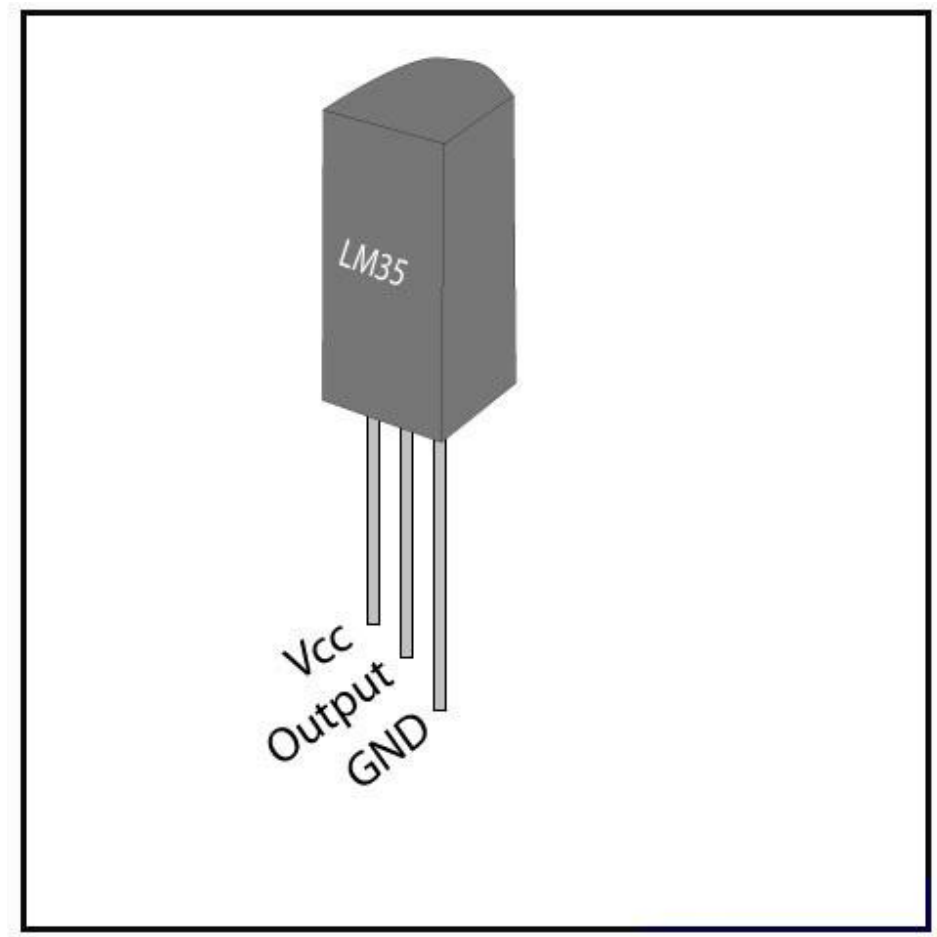

\section{MQ-5:}

The MQ5 ${ }^{[7]}$ is used in gas leakage detecting equipment in consumer and industry applications; this sensor is suitable for detecting LPG, natural gas, coal gas. Avoid the noise of alcohol, cooking fumes and cigarette smoke. The sensitivity can be adjusted by the potentiometer.






\begin{tabular}{|c|c|c|c|}
\hline \multicolumn{3}{|c|}{ Model No. } & MQ-5 \\
\hline \multicolumn{3}{|c|}{ Sensor Type } & Semiconductor \\
\hline \multicolumn{3}{|c|}{ Standard Encapsulation } & Bakelite (Black Bakelite) \\
\hline \multicolumn{3}{|c|}{ Detection Gas } & LPG, Methane, coal gas \\
\hline \multicolumn{3}{|c|}{ Concentration } & 300-10000ppm( Methane, Propane, Butane, H2) \\
\hline \multirow{3}{*}{ Circuit } & Loop Voltage & $V_{c}$ & $\leq 24 \mathrm{~V} D C$ \\
\hline & Heater Voltage & $\mathrm{VH}_{\mathrm{H}}$ & $5.0 \mathrm{~V} \pm 0.2 \mathrm{~V} \mathrm{AC}$ or $\mathrm{DC}$ \\
\hline & Load Resistance & $\overline{\mathrm{RL}}$ & Adjustable \\
\hline \multirow{5}{*}{ Character } & Heater Resistance & $\mathrm{RH}$ & $31 \Omega \pm 3 \Omega$ Room Tem. \\
\hline & Heater consumption & $\mathrm{PH}$ & $\leq 900 \mathrm{~mW}$ \\
\hline & Sensing Resistance & $R_{s}$ & $2 \mathrm{~K} \Omega-20 \mathrm{~K} \Omega\left(\right.$ in $2000 \mathrm{ppm} \mathrm{C}_{3} \mathrm{H}_{8}$ ) \\
\hline & Sensitivity & $\mathrm{s}$ & $\mathrm{Rs}$ (in air)/Rs(1000ppm $\left.\mathrm{C}_{3} \mathrm{H}_{8}\right) \geq 5$ \\
\hline & Slope & $\alpha$ & $\leq 0.6(\mathrm{R} 1000 \mathrm{ppm} / \mathrm{R} 500 \mathrm{ppm} \mathrm{H} 2)$ \\
\hline \multirow{3}{*}{ Condition } & Tem. Humidity & & $20 \pm 265 \% \pm 5 \% \mathrm{RH}$ \\
\hline & \multicolumn{2}{|c|}{ Standard test circuit } & $V_{H}: 5.0 \mathrm{~V} \pm 0.1 \mathrm{Vc:5.0 \textrm {V } \pm 0 . 1 \mathrm { V }}$ \\
\hline & Preheat time & & Over 48 hours \\
\hline
\end{tabular}

\section{Vibration SW18015:}

This Vibration Sensor SW18015 ${ }^{[8][9]}$ use can triggered from any angle, and often used for flex, touch, vibration and shock measurements.

Sensitivity= very high .

Encapsulation: Unsealed 




Fig: movement of SW18015

Here,

$\mathrm{A}=4.5 \mathrm{~mm}$

$\mathrm{B}=10 \mathrm{~mm}$

$\mathrm{C}=8 \mathrm{~mm}$

$\mathrm{D}=8-13 \mathrm{~mm}$

$\mathrm{E}=0.5 \mathrm{~mm}$

$\mathrm{F}=0.15 \mathrm{~mm}$

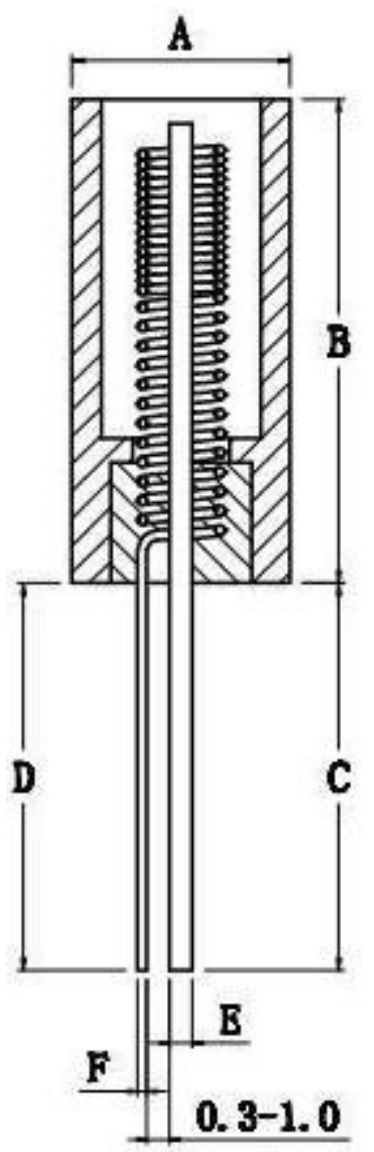

Fig: structure of SW18015 


\subsection{K pot:}

A potentiometer, informally a pot, is a three-terminal resistor with a sliding contact that forms an adjustable voltage divider. If only two terminals are used, one end and the wiper, it acts as a variable resistor or rheostat.

\section{Crystal oscillator:}

A crystal oscillator ${ }^{[11]}$ is an electronic oscillator circuit that uses the mechanical resonance of a vibrating crystal of piezoelectric material to create an electrical signal with a very precise frequency. This frequency is commonly used to keep track of time (as in quartz wristwatches), to provide a stable clock signal for digital integrated circuits, and to stabilize frequencies for radio transmitters and receivers.

\section{LCD Display:}

It is a 16 Characters x 2 Lines LCD, Parallel Display with LED backlit display.

The $\operatorname{LCD}^{[10]}$ is based on the ever popular Hitachi HD44780 parallel interface chipset. Lots of free code available for just about any microcontroller you can think of including the Basic ATOM series. 


\section{Project working procedure:}

Initially we studied about all the sensors and our microcontroller. Then we planned to study about the coding part to synchronies the microcontroller with the sensors. We found that micro $\mathrm{C}$ is the programming language for the microcontrollers, to make it work. Then we started to design our project. Firstly, we worked on the coding for the project and the hardware setup.

As our system will sense the temperature, smoke, vibration and humidity, we wrote a code on Micro $\mathrm{C}$ to get the feedback from the sensors. We also designed the code in such a way, so that we can get visual outputs on the monitors using USB interfacing.

Using "PICkit" burner, which is the tool for burning codes into microcontrollers, we burn our microcontroller PIC18f2550 as we needed with the prepared code for getting values from sensors and USB interfacing codes to connect it with PC.

We placed our microcontroller PIC18f2550 on a breadboard. With it we used a 12 $\mathrm{MHz}$ crystal oscillator. We had to use it as the microcontroller (PIC18f2550) is real time dependent, so an accurate system clock is essential to keep time with the outside world.

Then we placed the temperature sensor LM-35 and connected it to the microcontroller PIC18f2550 with the help of datasheet. After doing some changes, we found our LM-35 working fine and showing the temperature. 
The other sensors, Humidity sensor HSM-20g, Smoke Sensor MQ-5 and vibration switch SW18015 are also placed on the same board according to their respected datasheet, in the same procedure by testing their outputs. We also used a $100 \mathrm{~K}$ resistor to limit the input voltage.

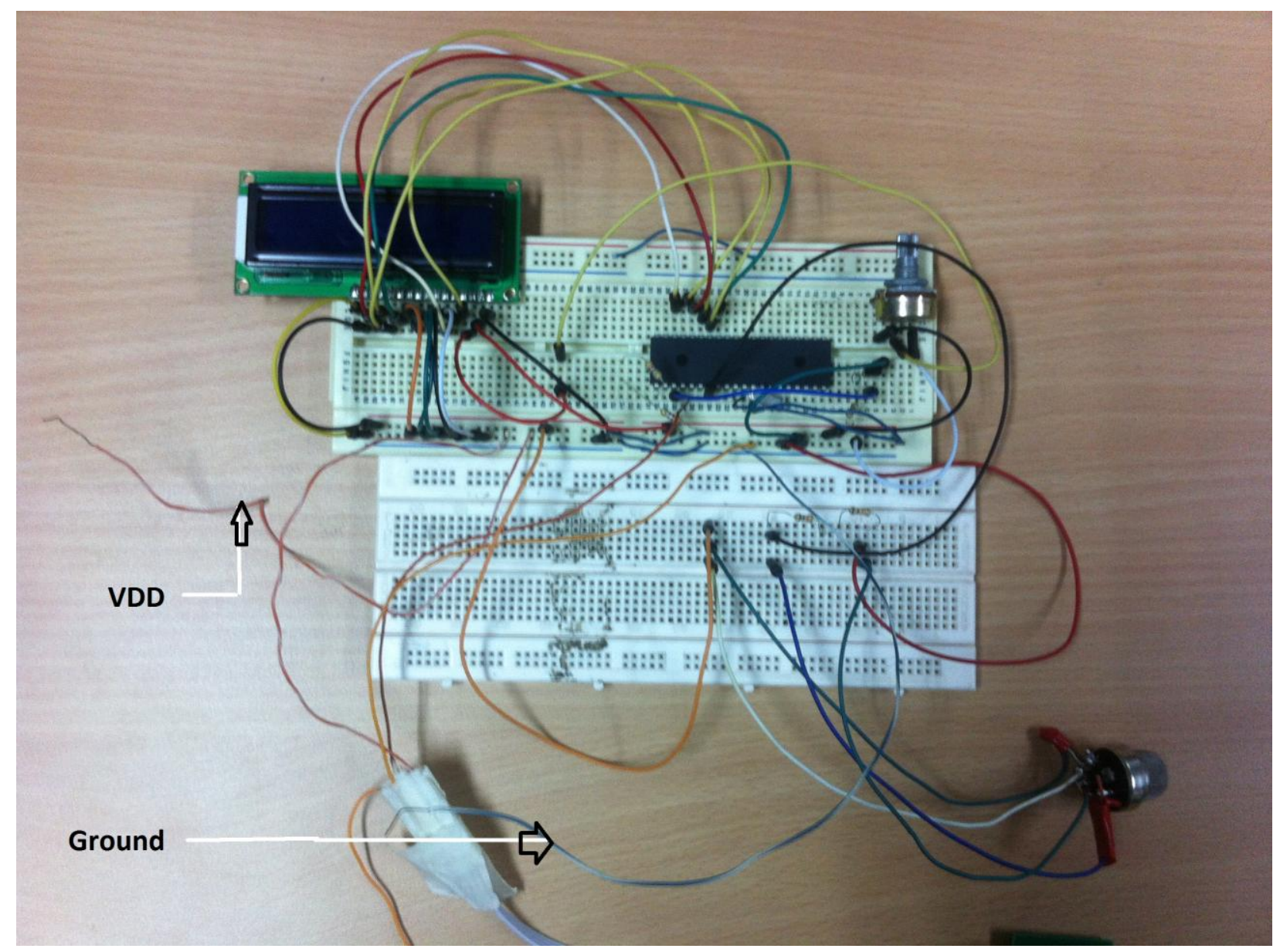

Fig: Physical Circuit setup (Phase: 1). 
Block Diagram:

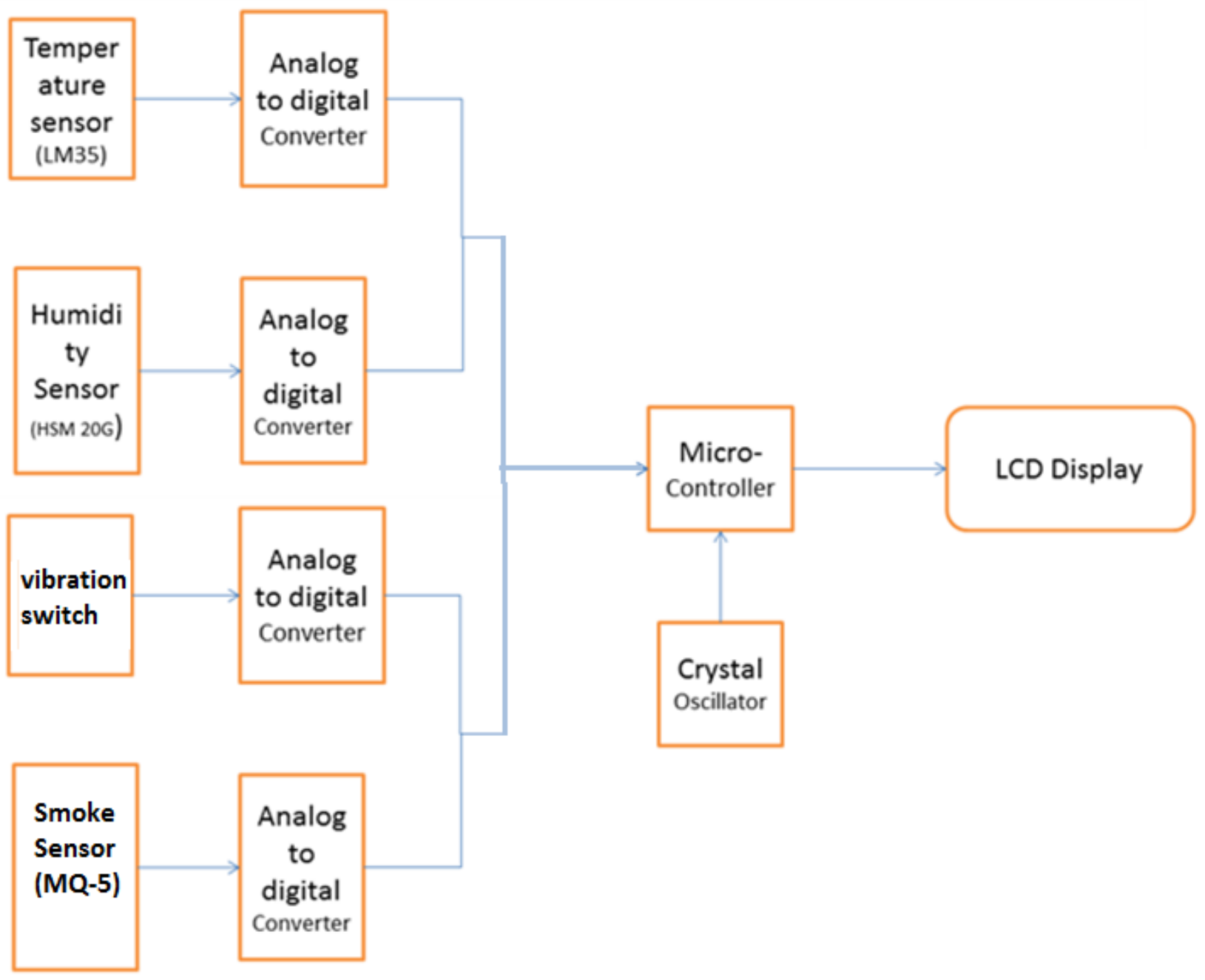

Fig: Block Diagram Phase 1. 


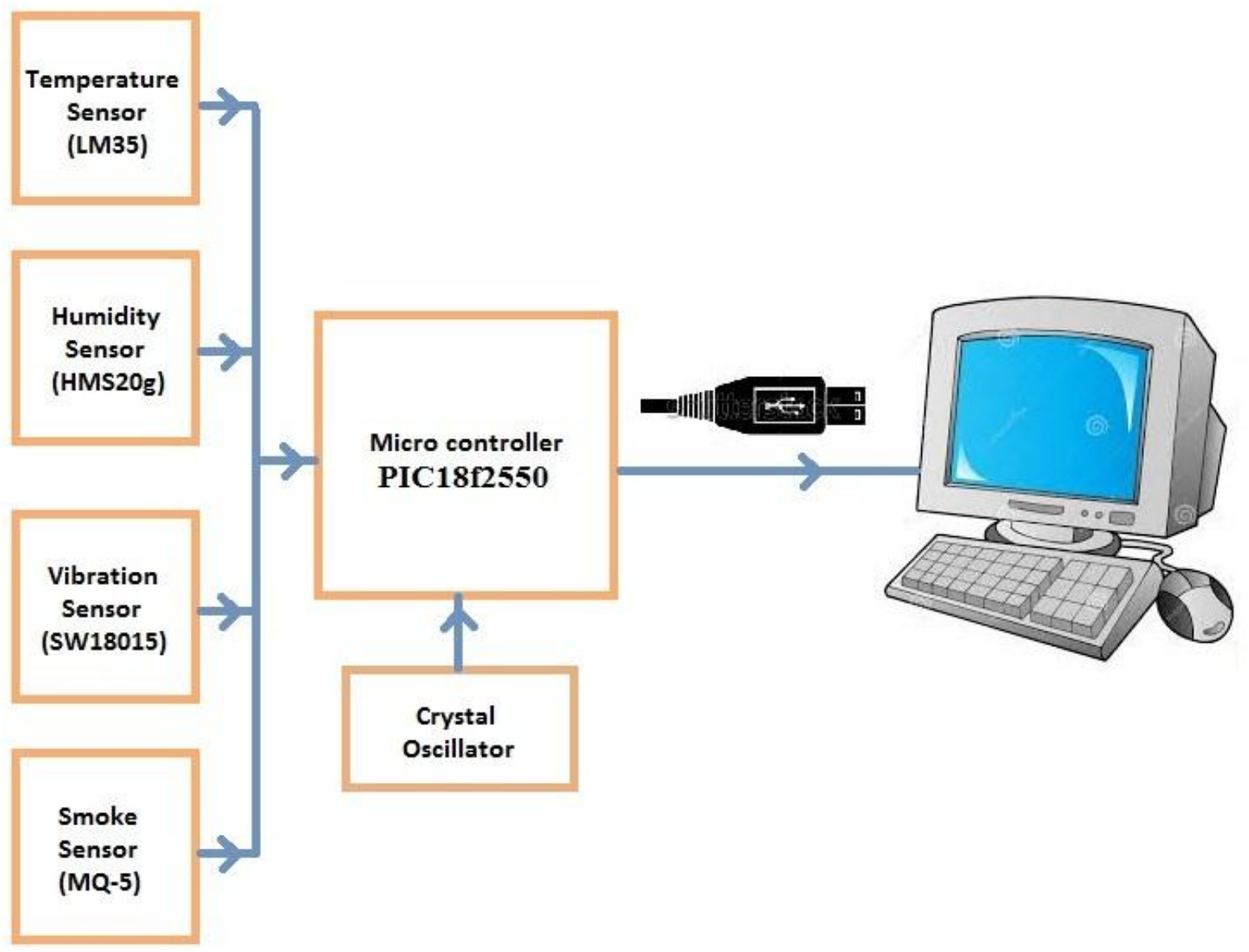

Fig: Block Diagram of the complete project. 


\section{Schematic Diagrams:}

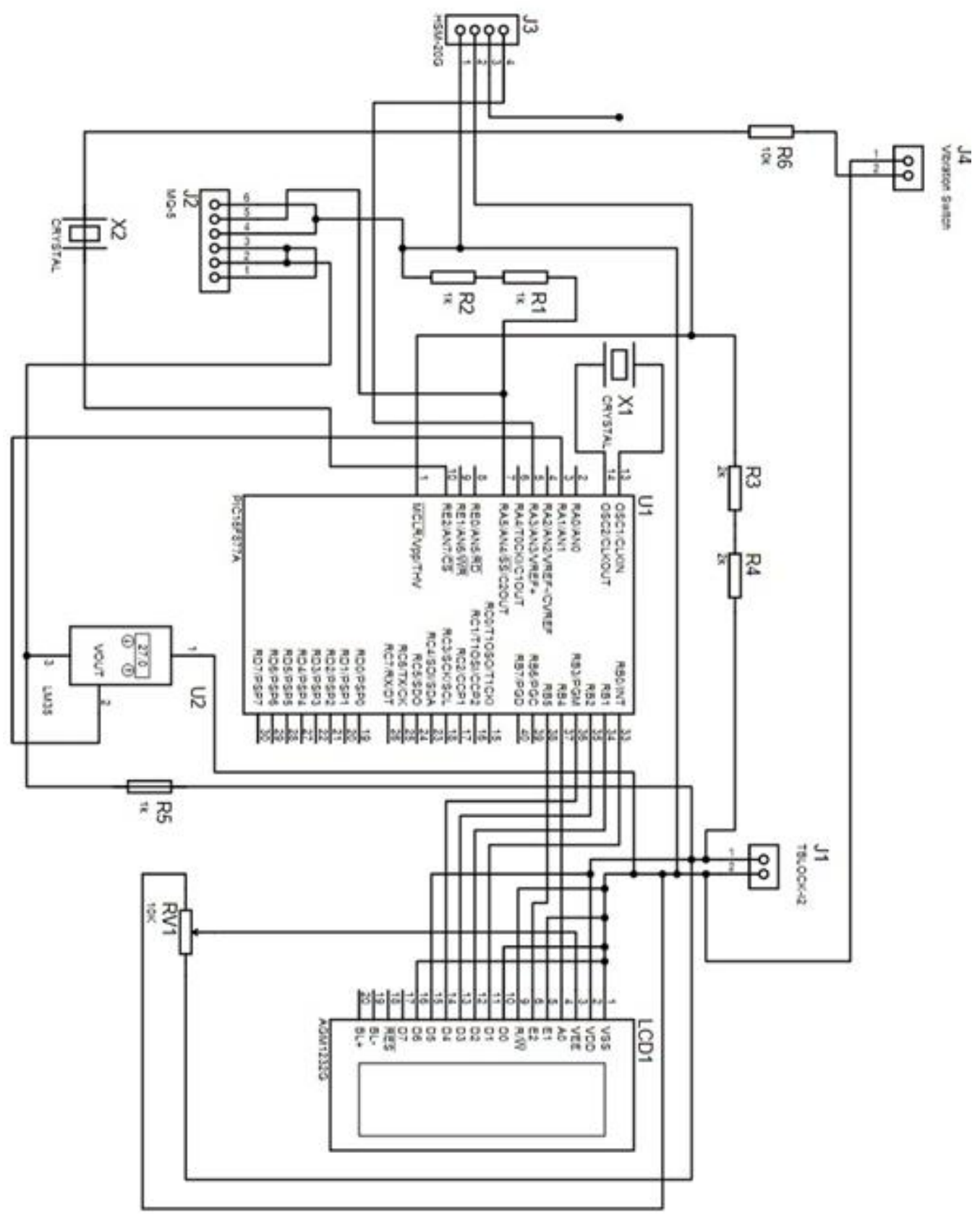

Fig: Schematic of the whole circuit

here,

$\mathrm{J} 1=\mathrm{DC} \quad$ voltage source, $\mathrm{J} 2=\mathrm{MQ}-5, \quad \mathrm{~J} 3=\mathrm{hsm}-20 \mathrm{~g}, \mathrm{~J} 4=\mathrm{Vibration}$ switch, U2=LM-35, $\mathrm{X} 1=\mathrm{X} 2=$ Cristal Oscillator, $\mathrm{R} 1=\mathrm{R} 2=\mathrm{R} 3=\mathrm{R} 4=\mathrm{R} 5=1 \mathrm{~K}$ ohm, $\mathrm{RV} 1=10 \mathrm{~K}$ ohm, LCD1=LCD Display. 


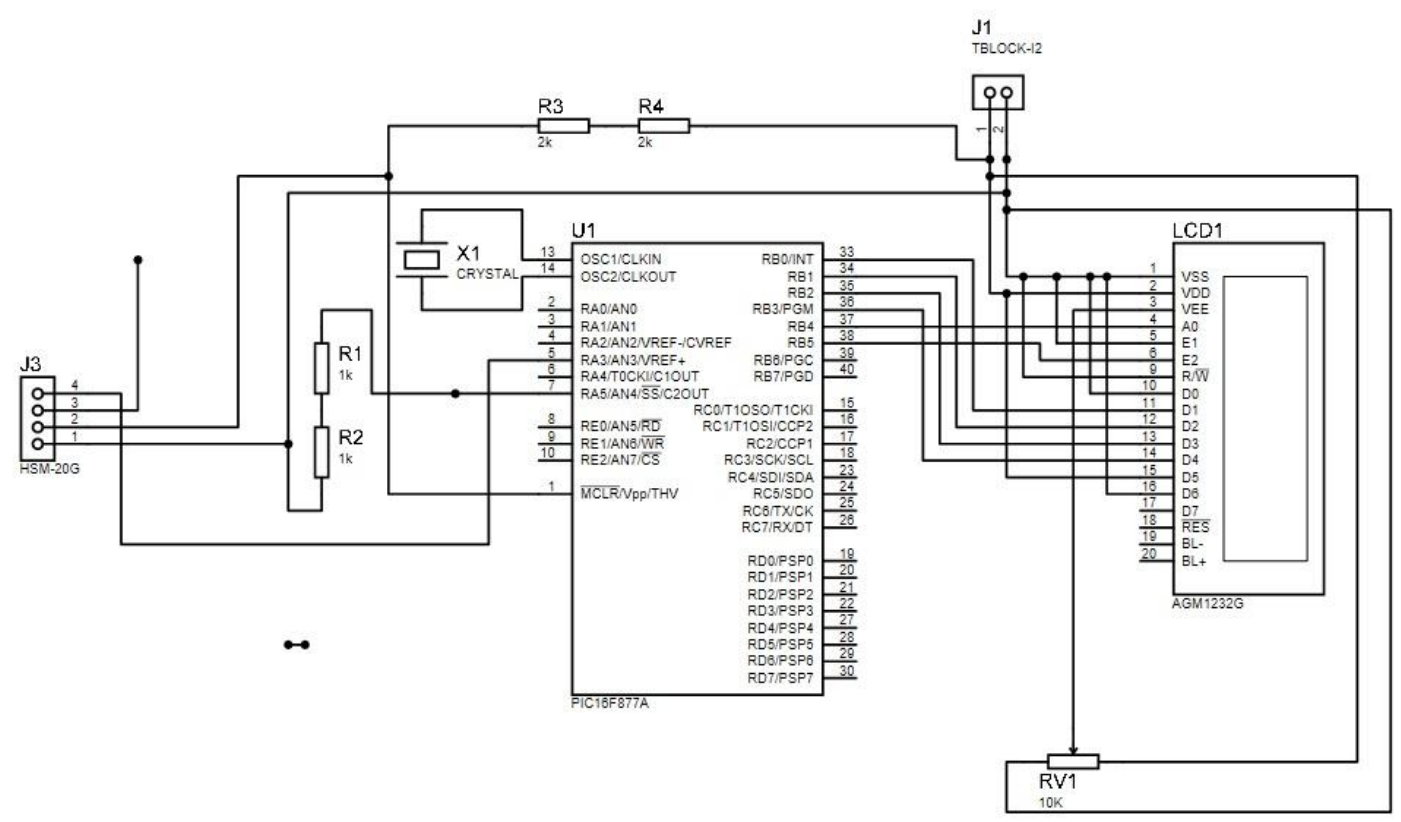

Fig: Schematic diagram of HSM-20g sensor connection.

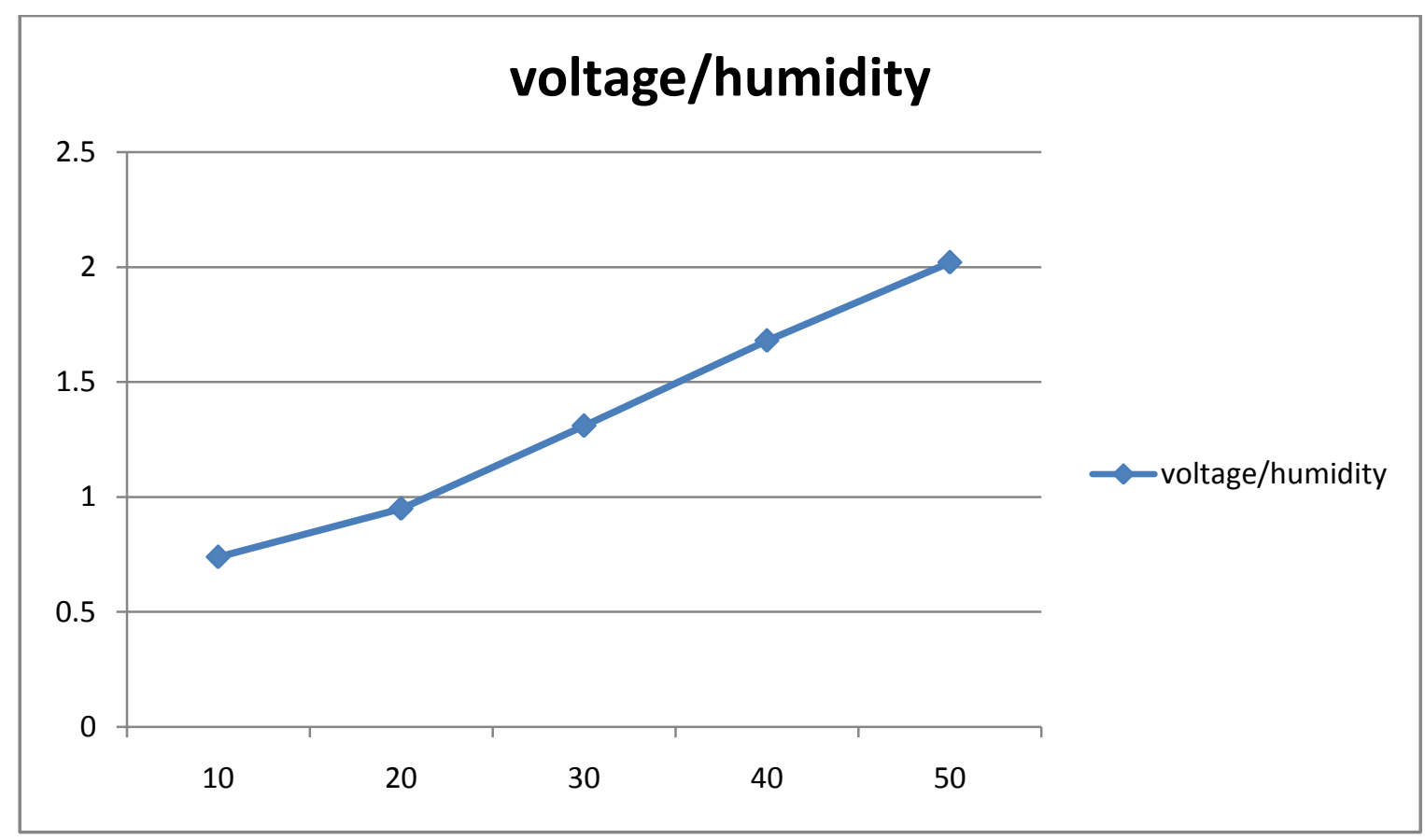

Fig: Performance analysis of HSM-20g 


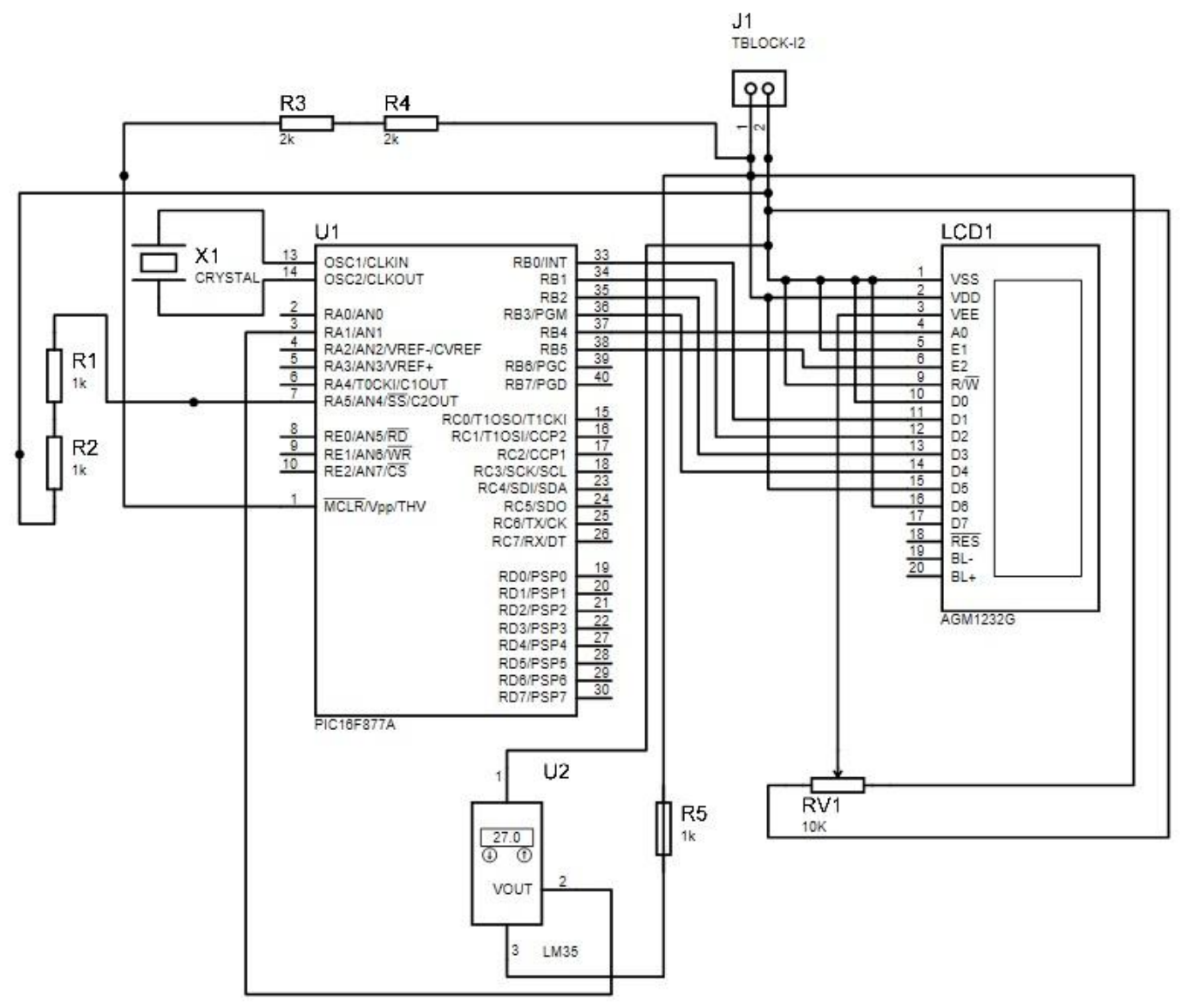

Fig: Schematic diagram of LM-35 sensor connection.

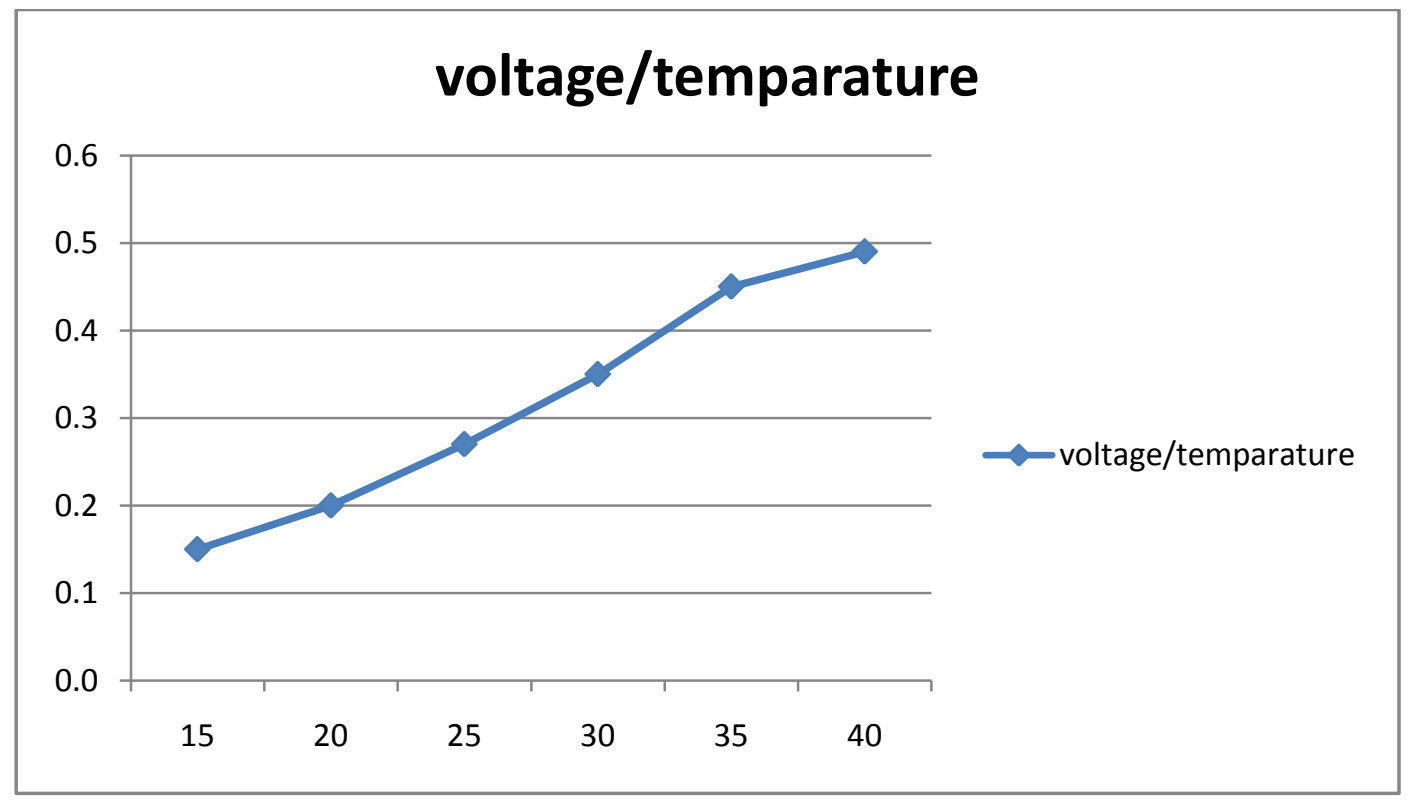

Fig: Performance analysis of LM-35 




Fig: Schematic diagram of MQ-5 sensor connection.



Fig: Schematic diagram of Vibration Switch connection. 


\section{Software Building:}

With the help of Mathlab, $\mathrm{C}$ coding and some basic algorithms, we mada a interfacing softwere by which we can show the outputs graphically in a GUI window. When the microcontroller sends the sets of values from the sensors in small packets, the mathlab processes it accordingly into a graphical output and shows like a bar in a box either in green or red color .

The visual softwere has the ability to show what is the temparature level, humidity level, vibration presence and smoke/gas presence around the sensors in a small window .

The GUI window have four boxes. Each box individually shows the temparature level, humidity level, vibration presence and smoke/gas presence. When the values are lower than the risk level, then the boxes will have a green bar and no sound. But when the valus are in alarming state then the bar will turn into red and thus the alarm will start to buzz. Every time the alarm will continue for 8 seconds.

These values can be changed accordigly as these values will be different from one device to another. In the code, by setting the normal value range and maximum safe Vlues for every sencor, the sencitivity of each sensor can be changed, even manupulated.

It has a switch by which the softwere can be turn on or turn off. When it will be turned off from the GUI window, the whole setup will be disabled untuill next cycle. Depending on the machine, on which this device will be used, it is even possible to use a "kill switch" to turn that off instantly in the time of emergency. 


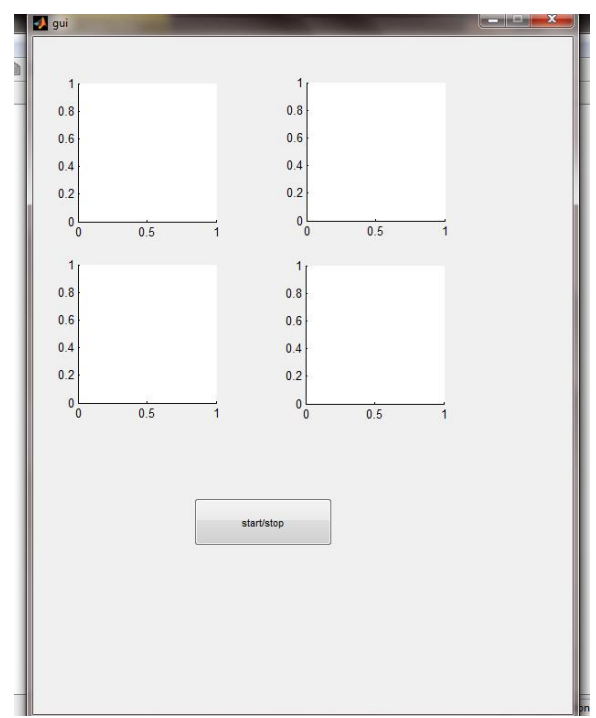

Fig: When the software is off
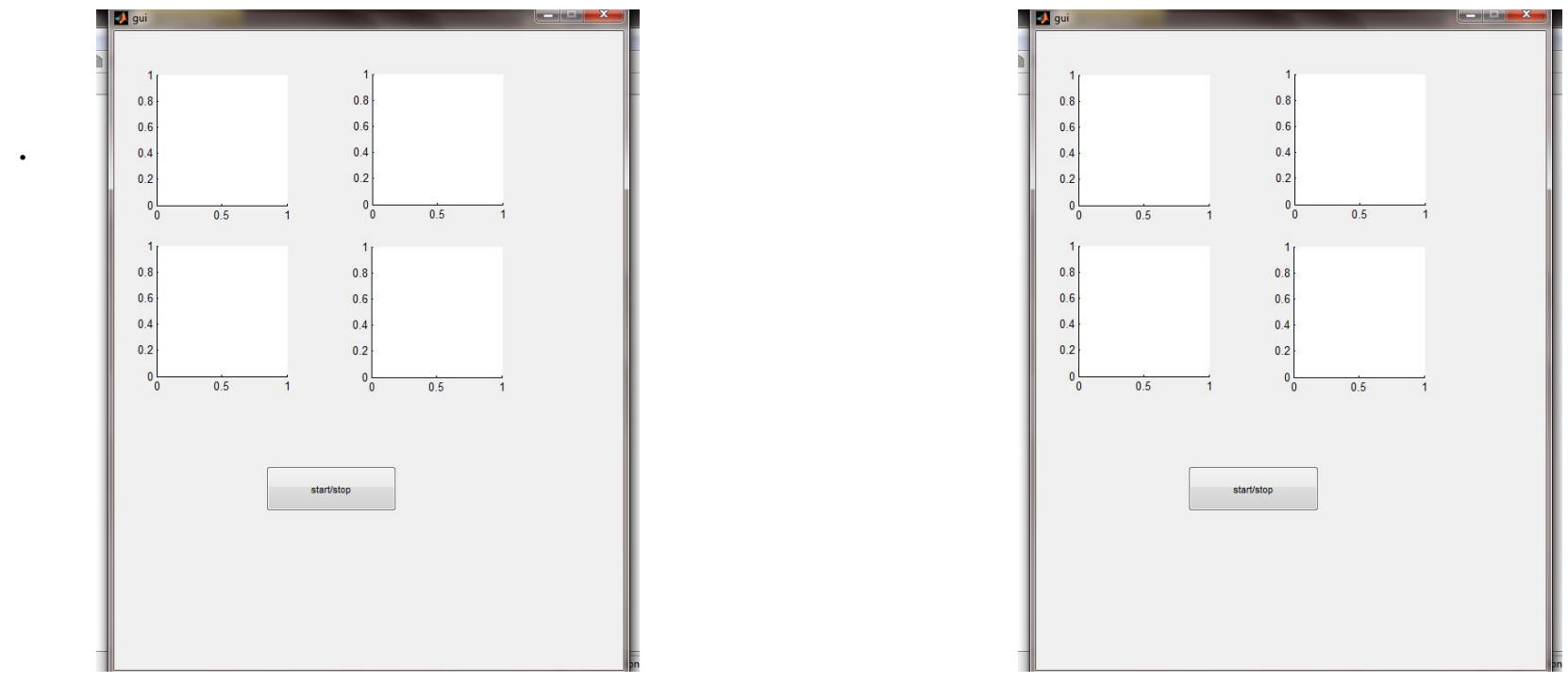

Fig: When the software is on

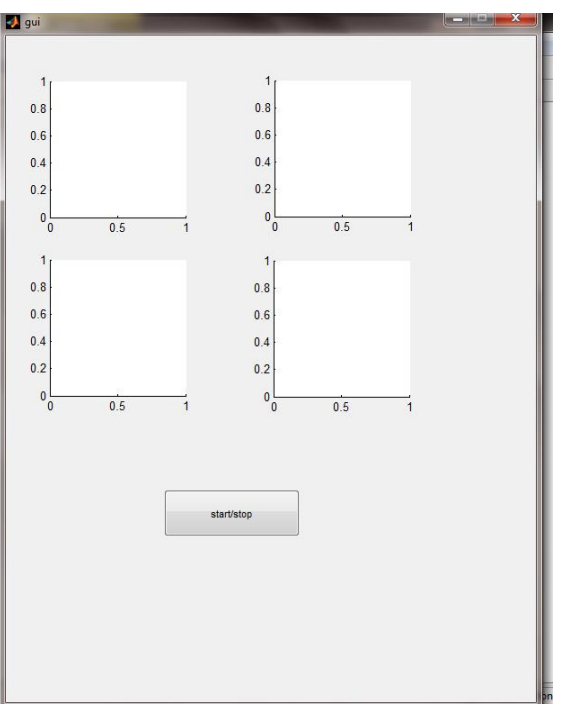

Fig: When the software is idle

and all are in safe zone 
A Distanced Machinery Controlling and Monitoring Guardian 


\section{Time Scale (work schedule):}

Our working progress according to dates are given below,

\begin{tabular}{|c|l|}
\hline \multicolumn{1}{|c|}{ Date } & \multicolumn{1}{c|}{ Working Progress } \\
\hline $24 / 1 / 2013$ & Conduct research on machinery hazards. \\
\hline $31 / 1 / 2013$ & Came up with the sensors activities. \\
\hline $5 / 2 / 2013$ & Deciding name of the project and work division. \\
\hline $12 / 2 / 2013$ & Working with smoke sensor (MQ5)\& PIC16f877A. \\
\hline $19 / 2 / 2013$ & Working with LM-35 \& PIC16f877A. \\
\hline $12 / 3 / 2013$ & Burn codes for the sensors in the PIC. \\
\hline $19 / 3 / 2013$ & Report writing (pre-thesis). \\
\hline $26 / 3 / 2013$ & Research with Humidity sensors. \\
\hline $29 / 5 / 2013$ & Working with HSM-20g \& PIC16f877A. \\
\hline $5 / 6 / 2013$ & Research with sound and vibration sensors. \\
\hline $19 / 6 / 2013$ & Building a manual vibration sensor. \\
\hline $26 / 6 / 2013$ & Designing Block diagrams. \\
\hline $17 / 7 / 2013$ & Designing Schematic diagrams. \\
\hline $24 / 7 / 2013$ & Working with crystal oscillator. \\
\hline & \\
\hline 50
\end{tabular}




\begin{tabular}{|c|l|}
\hline \multicolumn{1}{|c|}{ Date } & \multicolumn{1}{c|}{ Working Progress } \\
\hline $31 / 7 / 2013$ & $\begin{array}{l}\text { researching on serial connection compatibility, } \\
\text { facing problem with serial connection. }\end{array}$ \\
\hline $5 / 8 / 2013$ & $\begin{array}{l}\text { Replacing the interfacing connection from serial to } \\
\text { USB, substituting PIC16f877A with PIC18F2550. }\end{array}$ \\
\hline $7 / 8 / 2013$ & $\begin{array}{l}\text { Report writing (thesis, 2nd semester)Burn codes for } \\
\text { the sensors for the new PIC. }\end{array}$ \\
\hline $26 / 9 / 2013$ & Creating such environments for the project. \\
\hline $24 / 10 / 2013$ & Designing a PCB. \\
\hline $31 / 10 / 2013$ & Replace the equipments in the PCB. \\
\hline $21 / 10 / 2013$ & Observing PCB problems, redesign a PCB. \\
\hline $14 / 11 / 2013$ & Built a software for interfacing with a computer. \\
\hline $28 / 11 / 2013$ & Interfacing with a computer. \\
\hline $19 / 12 / 2013$ & Final report writing and preparing the presentation \\
\hline slides. \\
\hline Submitting report.
\end{tabular}




\section{Pitfalls:}

In the beginning we decided to work with PIC16f877A, but we faced many problems interfacing this PIC with modern computers because this PIC can only be connected with computers through serial ports, then we decided to use a serial port to USB converter, but in that case we faced many difficulties such as late connection, discontinuity and etc, then we decided to use PIC18F2550 instead of using PIC16f877A, as a result we got our expecting results and fixed our project to go with PIC18F2550.

Again due to multiple codes changing, we accidently broke PIC18F2550 pins once. This led us into time consuming finding of PIC18F2550 again.

Another problem we faced was with vibration switch $S W 18010$, there was no chip connected with it like $S W 18015$ has. As a result while working with $S W 18010$ it was burned several times, we were also facing some coding difficulties, finding sample coding for SW18015 was very hard. So we changed SW18010 with SW18015 and moved forward with our project.

With HSM20g the values we were facing for temperature were fluctuating very much. The reason was there was a built in temperature sensor which was disturbing the data of $\mathbf{L M 3 5}$, so we needed to disconnected the cable of temperature sensor from $\boldsymbol{H S M 2 0 g}$, this problem was discovered by our project coordinator Dr.Md. KhalilurRhaman.

Last but not the least we were facing problem with PCB designing. We designed a two layer PCB design but for some difficulties we were unable to be present at the PCB printing labs. 
A Distanced Machinery Controlling and Monitoring Guardian

\section{Expenses:}

\begin{tabular}{|l|c|c|c|}
\hline \multicolumn{1}{|c|}{ Element } & Quantity & Rate(tk) & Price(tk) \\
\hline PIC 18f2550 & 3 & 400 & 1200 \\
\hline MQ5 & 1 & 560 & 560 \\
\hline HSM20g & 2 & 470 & 940 \\
\hline SW18015 & 2 & 200 & 400 \\
\hline LM35 & 2 & 80 & 160 \\
\hline USB cable & 2 & 80 & 160 \\
\hline USB Controller & 3 & 42 & 126 \\
\hline Miscellaneous(resistors, pot) & & 50 & 24 \\
\hline Crystal oscillator & 2 & 12 & 750 \\
\hline PCB designing & 3 & 250 & 50 \\
\hline
\end{tabular}

Total Price:

3,410 tk 


\section{Future plan:}

$21^{\text {st }}$ century is the century of modern engineering and technology with anticipation of fully automated gadgets and equipment to make life more easy and secured. Modern researches are on developing automated and S.M.A.R.T. (SelfMonitoring, Analysis and Reporting Technology) machineries so that the risk of accidents reduces in significant amount.

Depending on this research, we are highly motivated and have the plan to improve our project into a total automated system so that if anything goes wrong or the machinery faces any kind of unstable working situation or environment, which might decrease the life span of it or damage it in any way, then our system will take necessary steps to prevent it either stopping it or taking further action by alarming the technician team or other way. Currently we are focused to combine all the sensors and have real time effective output. But we are looking forward to develop a system which will include a wireless connection. It will allow the user to monitor the machine from a remote place and give instruction. If any direction is needed to run the machine the direction will be followed by our system. In addition, we will prefer to establish it as a fully automated system. Automated systems have less manual operations, flexibility, reliability and more accurate. Due to this demand every field prefers automated control systems. Especially in the field of electronics automated systems are giving good performance. In the present scenario of war situations, unmanned systems plays very important role to minimize human losses. So our system is very useful to do operations in hazardous situation where human can hardly do anything. We are planning to give the total control of a machine to our system which will monitor, detect problems and resolve the problems. Moreover, we will add more sensors to get mere detail 
information about the environment so that the technician group will be well prepared for any hazards threat that is present in the machine room.

\section{Future prospect:}

Nowadays many machines have self monitoring system, but those are present in highly expensive machines. So in order to run a machine smoothly which has no self monitoring system a more efficient and cheaper solution was required. This project can be much handier to use in any type of environment. In contrast, this project has a very good future prospect as the latest technological monitoring systems and equipment are highly expensive and these cannot be used vastly in our country. But our project can be used as a cheaper replacement of those. So someday we can expect to give support to a huge amount of heavy industry with devices based on our project. 


\section{References}

1. http://www.marineinsight.com/misc/marine-safety/10-extremely-dangerousengine-room-accidents/

2. http://www.microchip.com/wwwproducts/Devices.aspx?dDocName=en0102 80http://www.microchip.com/productselector/MCUProductSelector.html

3. http://massmind.org/techref/microchip/pages.htm

4. http://www.waitingforfriday.com/index.php/Building_a_PIC18F_USB_devi cehttp://www.ti.com/product//m35

5. http://www.geeetech.com/wiki/index.php/Humidity_/Temperature_Sensor_ Module_HSM-20Ghttp://www.basicmicro.com/LCD-16x2-

Display_p_87.html

6. http://www.engineersgarage.com/electronic-components/lm35-sensordatasheet. http://www.engineersgarage.com/electronic-components/16x2lcd-module-datasheet

7. http://seeedstudio.com/wiki/Grove__Gas_Sensor\%28MQ5\%29http://www.alldatasheet.net/view.jsp?Searchwor $\mathrm{d}=\mathrm{HSM} 20 \mathrm{G}$

8. http://en.wikipedia.org/wiki/S.M.A.R.T..

9. http://www.all-spec.com/products/SW18015.html

10. http://www.engineersgarage.com/electronic-components/16x2-lcdmodule-datasheet

11. http://en.wikipedia.org/wiki/Crystal_oscillator 


\section{Appendix \\ (Codes of micro-controller)}

The section below is Variables required for calculation

unsignedintval,voltage,t,humidity_read;

float a;

TRISA = 0xFF;

Takes temperature input from ADC pin 1

val=ADC_Read(1); //Read Channel 0

Convert $A D C$ voltage input to temperature

$\mathrm{t}=$ val*0.48876; //temperature value

Takes humidity input from ADC pin 3

humidity_read=ADC_Read(3); //Read Channel 1

Convert ADC voltage input to humidity

val= (humidity_read/1023.0)*5; 
Additional calculation is require to get the actual humidity output, which is obtained using the following equation(here val is the direct value of the humidity sensor)

$\mathrm{a}=\left(\left(3.71 * \mathrm{val}^{*}\right.\right.$ val $*$ val $)-(20.65 *$ val * val $)+(64.81 *$ val $\left.)-27.44\right)$

humidity_read=a;

Converts temperature and humidity value to display in LCD

IntToStr(t, txt1); $\quad$ //convert temperature to string

IntToStr(humidity_read, txt2); $\quad$ //convert temperature to string

\section{Smoke}

\#include<avr/io.h>

\#include<adc_lib.h>

\#define ADC_VREF_TYPE 0x00

// Read the AD conversion result

unsignedintread_adc(unsigned char adc_input)

\{

ADMUX=adc_input $\mid A D C \_V R E F \_T Y P E ;$

// Start the AD conversion

$\operatorname{ADCSRA} \mid=0 \times 40$;

// Wait for the AD conversion to complete 
\% Last Modified by GUIDE v2.5 24-Dec-2013 22:55:49

\% Begin initialization code - DO NOT EDIT

gui_Singleton $=1$;

gui_State $=$ struct('gui_Name', mfilename, ...

'gui_Singleton', gui_singleton, ...

'gui_OpeningFen', @gui_OpeningFen, ...

'gui_OutputFen', @gui_OutputFen, ...

'gui_LayoutFen', [], ...

'gui_Callback', []);

ifnargin\&\&ischar (varargin $\{1\}$ )

gui_state.gui_Callback = str2func(varargin $\{1\})$;

end

ifnargout

[varargout $\{1$ :nargout $\}]=$ gui_mainfen (gui_State, $\operatorname{varargin}\{:\})$; else

gui_mainfon(gui_state, varargin $\{:\})$;

end

End initialization code - DO NOT EDIT

\%--- Executes just before gui is made visible.

functiongui_OpeningFcn(hobject, eventdata, handles, varargin)

\% This function has no output args, see OutputFcn.

\% hobject handle to figure

\% eventdata reserved - to be defined in a future version of MATLAB

\% handles structure with handles and user data (see GUIDATA)

o varargin command line arguments to gui (see VARARGIN)

\% Choose default command line output for gui

handles.output $=$ hobject;

\% Update handles structure 


\section{A Distanced Machinery Controlling and Monitoring Guardian}

guidata (hobject, handles);

\% UIWAIT makes gui wait for user response (see UIRESUME)

o uiwait (handles.figure1);

\% --- Outputs from this function are returned to the command line.

functionvarargout = gui_OutputFcn (hobject, eventdata, handles)

\% varargout cell array for returning output args (see VARARGOUT);

\% hobject handle to figure

\% eventdata reserved - to be defined in a future version of MATLAB

o handles structure with handles and user data (see GUIDATA)

\% Get default command line output from handles structure

varargout $\{1\}=$ handles.output;

\%--- Executes on button press in togglebuttonl.

function togglebutton1_Callback(hobject, eventdata, handles)

\% hobject handle to togglebuttonl (see GCBO)

o eventdata reserved - to be defined in a future version of MATLAB

o handles structure with handles and user data (see GUIDATA)

\% Hint: get(hobject, 'Value') returns toggle state of togglebuttonl

mySound = wavread ('ALARM.wav');

while get (hobject, 'Value')

humd = fopen ('humd.txt');

smok = fopen('smok.txt');

temp $=$ fopen ('temp.txt');

vibr $=$ fopen ('vibr.txt');

$\mathrm{flag}=0$

humidity= fscanf (humd, ' $\% \mathrm{~d}^{\prime}$ ) 


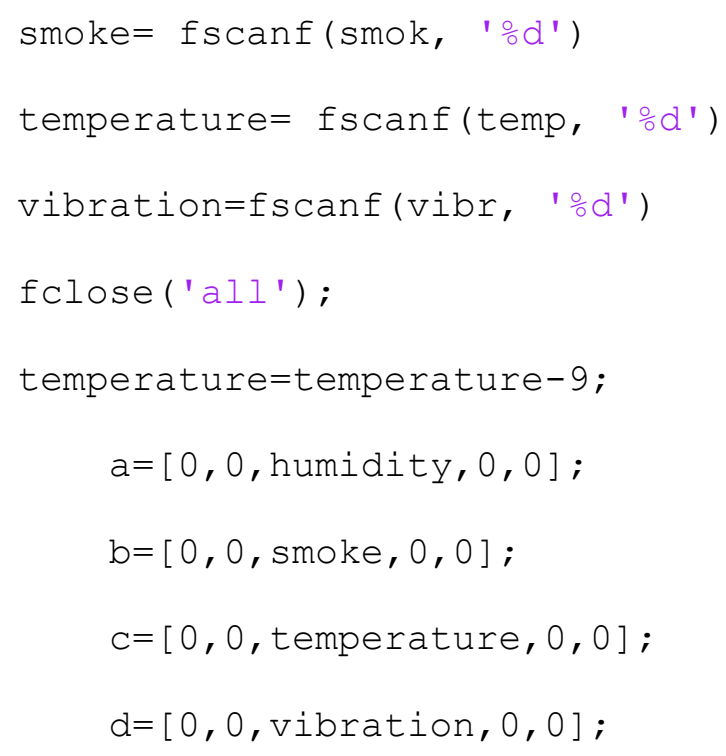


$x \_$temp $=$'r' ;

$\mathrm{flag}=1$

else

$x_{\text {_temp }}=\mathrm{g}^{\prime}$;

end;

if (vibration $>3.5$ )

x_vibe= 'r' ;

$\mathrm{flag}=1$

else

x_vibe= 'g' ;

end;

if $(\mathrm{flag}==1)$

sound (mySound)

end

$\circ \mathrm{x}$ temp $=$ 'r';

\% $\mathrm{x}$ smok='r';

x_vibe='r';

oplot (a) ;

axes (handles.axes1) ;

$\operatorname{bar}\left(\mathrm{c}, \mathrm{x}_{\text {_ temp }}\right.$ )

$y \lim ([0,100])$ 
title ('temperature')

axes (handles.axes2);

$\operatorname{bar}\left(10, \mathrm{x} \_s m o k\right)$

$\circ y \lim ([0,20])$

title ('Smoke')

axes (handles.axes3);

$\operatorname{bar}\left(\mathrm{a}, \mathrm{x} \_\right.$hum $)$

$y \lim ([0,100])$

title ('Humidity')

axes (handles.axes4);

$\operatorname{bar}\left(10, \mathrm{x} \_\mathrm{vibe}\right)$

$y \lim ([0,10])$

title ('Vibration')

pause (1)

end 